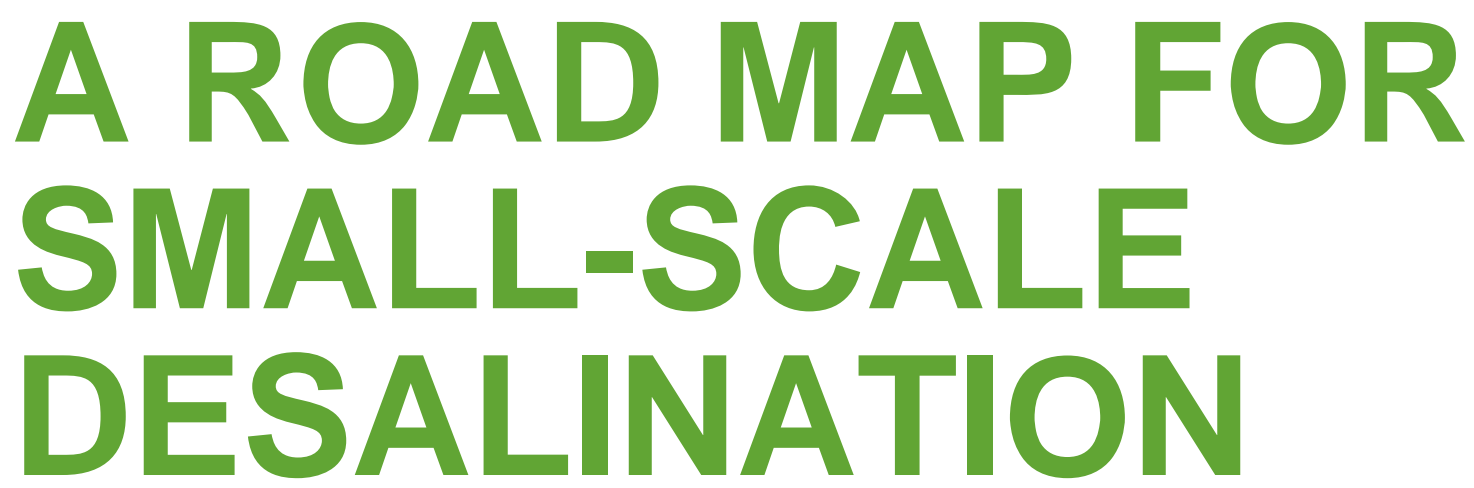

\title{
An overview of existing and emerging technology solutions for cost-efficient and low-energy desalination in South and Southeast Asia
}

\section{KATHRYN S. BODEN AND CHINMAYEE V. SUBBAN}

University of California, Berkeley \& Lawrence Berkeley National Laboratory

Asia is one of the hardest hit areas in the world in terms of intrusion of saline groundwater. In the near future, sea-level rise will cause further saltwater intrusion into water resources, while an increasing number of water control structures will increase river salinity - threatening fresh water supplies for drinking and livelihoods, irreversibly impacting people's lives and livelihoods. Desalination technologies typically require high energy inputs, as well as specialized maintenance procedures, to function sustainably - rendering them inappropriate for water production in low-income areas. The focus of this paper is the development of a 'Road Map' for scalable, low energy-input solutions for small-scale desalination. 


\section{CONTENTS}

$\begin{array}{ll}\text { Acknowledgements } & 3\end{array}$

Acronyms \& abbreviations $\quad 4$

$\begin{array}{ll}\text { Executive summary } & 5\end{array}$

$\begin{array}{ll}\text { Introduction: tapping into saline sources } & 6\end{array}$

1. Overview of desalination technologies 9

$\begin{array}{ll}\text { 1.1 Saline water sources } & 9\end{array}$

$\begin{array}{ll}1.2 \text { Introduction to desalination } & 10\end{array}$

1.3 Desalination technologies $\quad 11$

1.4 Desalination water treatment 25

2. Energy needs and cost of desalination technologies 28

$\begin{array}{ll}2.1 \text { Energy } & 28\end{array}$

$\begin{array}{ll}2.2 \text { Cost } & 35\end{array}$

3. Community-scale desalination facilities 43

3.1 Solar-powered electrodialysis in India 43

3.2 Membrane capacitive deionization in India 44

3.3 Solar-powered reverse osmosis in India 45

3.4 Solar still distillation in Bangladesh 46

3.5 Wave-powered reverse osmosis in Puerto Rico 46

4. Conclusion and recommendations 49

$\begin{array}{ll}\text { Appendix } & 56\end{array}$

$\begin{array}{ll}\text { Notes } & 62\end{array}$ 


\section{ACKNOWLEDGEMENTS}

This report was commissioned by Tom Wildman at Oxfam GB, and written by Kathryn S. Boden and Chinmayee V. Subban, respectively from the University of California, Berkeley and Lawrence Berkeley National Laboratory.

\section{Kathryn S. Boden}
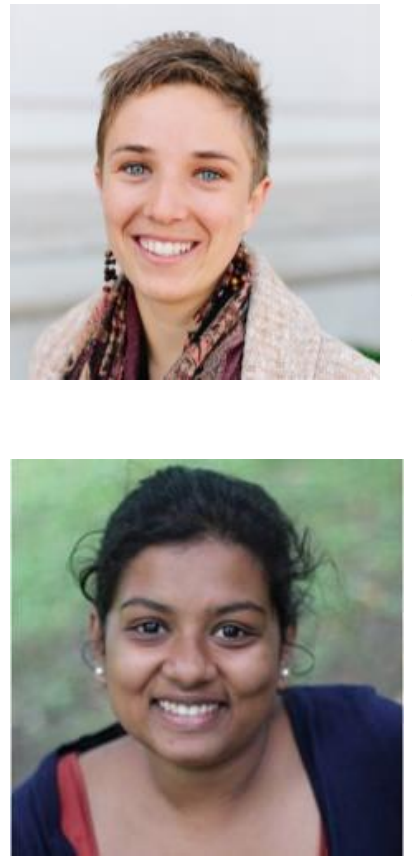

Kathryn Boden is a Research and Development Engineer at UC Berkeley. Her academic training is in Physics and the focus of her work is to research, develop, and implement water treatment systems that are safe, sustainable, and equitable. She has worked on applying an arsenic removal technology as a water treatment system in rural India and as remediation tool for coal ash ponds in the United States. Her work will continue to investigate the availability of contaminant free water in the wake of a changing climate.

\section{Chinmayee V. Subban}

Chinmayee Subban is a Research Scientist at Lawrence Berkeley National Lab. She is keen on applying her materials chemistry knowledge to design socially relevant and impactful water treatment technologies. Her prior research focused on synthesis and characterization of new materials for energy technologies such as $\mathrm{Li}$ ion batteries and hydrogen fuel cells. Chinmayee received a Ph.D. in Chemistry from Cornell University and a B.S. in Chemistry and Biology from Linfield College.

Oxfam also acknowledges the assistance of Tom Wildman, Jola Miziniak, Anne Cossutta and David Wilson in the production of this report. 


\section{ACRONYMS \& ABBREVIATIONS}

\begin{tabular}{ll} 
AC & Alternating current \\
AD & Adsorption distillation \\
AEM & Anion exchange membrane \\
CEM & Cation exchange membrane \\
DC & Direct current \\
ED & Electrodialysis \\
EDR & Electrodialysis reversal \\
FO & Forward osmosis \\
kWh & Kilowatt hour \\
L/day & Litres per day \\
LPH & Litres per hour \\
mCDI & Membrane capacitive deionization \\
MD & Membrane distillation \\
MED & Multiple-effect distillation \\
mg/L & milligrams per litre \\
MSF & Multi-stage flash distillation \\
nm & Nanometre \\
ppm & Parts per million \\
psi & Pounds per square inch \\
PV & Photovoltaic \\
R\&D & Research and development \\
RO & Reverse osmosis \\
SSD & Solar still distillation \\
TDS & Total dissolved solids \\
Ti & Titanium \\
UV & Ultraviolet \\
VCD & Vapour compression distillation \\
ZLD & Zero liquid discharge \\
& \\
\hline
\end{tabular}




\title{
EXECUTIVE SUMMARY
}

\author{
Based on a survey of commercially available, small-scale desalination \\ facilities (1-10 $\left.\mathrm{m}^{3} / \mathrm{day}\right)$ in South Asia, Oxfam recommends the use of \\ reverse osmosis $(\mathrm{RO})$ as the most effective technology.
}

$\mathrm{RO}$ has been shown to work at various scales for decades and involves considerably lower risks compared with emerging technology alternatives. Having reached economies of scale, the cost of a small RO system and associated replacement parts is likely to be cheaper than that of alternative options of a similar size. Further, the widespread use and availability of RO technology improves the chances of finding local technical expertise for operation and maintenance. There are several examples of $\mathrm{RO}$ facilities being powered off-grid, using renewable energy sources such as the sun. However, these facilities are significantly more expensive than grid-powered RO due to the additional cost of power generation and the storage systems required.

Although RO is Oxfam's top recommendation, there are significant drawbacks to the technology, including high maintenance costs, low water recovery rates, the burden of disposing of large volumes of brine waste, and high energy consumption for treating mildly brackish water (with total dissolved solids (TDS) of less than 3,500 parts per million (ppm)). Considering these drawbacks, the authors have closely examined three alternative desalination technologies to RO: solar still distillation (SSD), membrane capacitive deionization (mCDI) and electrodialysis reversal (EDR).

SSD is a simple technology powered entirely by the sun, which minimizes operational expenses. However, it has high capital cost and very low water output (only tens of litres of water per day). Facilities necessary to meet community water needs require a significant area of land. The combination of low output and high capital cost makes SSD the most expensive option for communities in South Asia in terms of price per litre of treated water.

\section{For these reasons, Oxfam recommends SSD for single households and not for community-scale installations.}

For waters with TDS of less than 3,500 ppm, both $\mathrm{mCDI}$ and EDR show great promise in being more energy-efficient and easier to maintain than RO. They are known to have higher water recovery rates (80-95\%) compared with single-pass $\mathrm{RO}(25-50 \%)$. However, $\mathrm{mCDI}$ and EDR remain on the fringes of the desalination market as they are newly commercialized technologies and, as a result, are more expensive than $\mathrm{RO}$ and involve higher risks of failure. Theory suggests charge-based separation such as $\mathrm{mCDI}$ and EDR as more energy-efficient for sources up to $5,000 \mathrm{ppm}$, however, in practice this salinity max will be considerably lower. While mCDI and EDR are better for low salinity sources, they have mostly been demonstrated for feed waters less than 3,500 ppm. Comparing $\mathrm{mCDI}$ and EDR technologies, mCDI has been optimized for drinking water treatment while EDR is used mainly for industrial applications. Further, $\mathrm{mCDI}$ is being widely commercialized in South Asia, with companies planning to manufacture units locally as a way to both reduce cost and increase market penetration.

Considering these factors, if an alternative to RO is highly desired, Oxfam recommends $\mathrm{mCDI}$ for low-salinity brackish sources with TDS of less than 3,500 ppm. 


\section{INTRODUCTION: TAPPING INTO SALINE SOURCES}

Water is essential to sustain human life; however, most of the water on the planet contains high concentrations of salts, making it unsuitable for human consumption. The ocean is an obvious example of a saline source but even among groundwater sources, which provide most of the world's drinking water supply, more is saline than fresh (Table 1). ${ }^{1}$ The issue of saline groundwater is particularly salient in South Asia.

\section{A staggering $73 \%$ of villages in India} rely solely on groundwater sources to meet their drinking water needs and, with nearly $60 \%$ of all groundwater in India saline, millions of people face severe shortages of fresh water.
Table 1: The world's water resources and their relative abundance

\begin{tabular}{|l|r|}
\hline Water resource & $\begin{array}{l}\text { \% of total water } \\
\text { on Earth }\end{array}$ \\
\hline Saline water & $\mathbf{9 7 . 5 \%}$ \\
\hline - Oceans and seas & $96.54 \%$ \\
\hline - Saline groundwater & $0.93 \%$ \\
\hline - Saltwater lakes & $0.006 \%$ \\
\hline Fresh water & $\mathbf{2 . 5 \%}$ \\
\hline - Glaciers and snow & $1.74 \%$ \\
\hline cover & \\
\hline - Fresh groundwater & $0.76 \%$ \\
\hline - Fresh lakes & $0.007 \%$ \\
\hline - Wetlands & $0.001 \%$ \\
\hline - Rivers & $0.0001 \%$ \\
\hline
\end{tabular}

Source: adapted from Wright and Winter (2014)

Affected communities have two options: pay high prices for bottled water or risk the health effects of drinking untreated saline sources. The global problem of insufficient supply of fresh water is only expected to get worse with climate change. The World Health Organization (WHO) predicts that by 2025 the changing climate will leave $50 \%$ of the world's population experiencing shortages of fresh water; the predicted water stress is shown in Figure $1 .^{2}$ This stress will be the result of many factors, including increased drought, population growth, increased pollution of existing fresh water sources, and increased intrusion of saline water into fresh groundwater supplies.

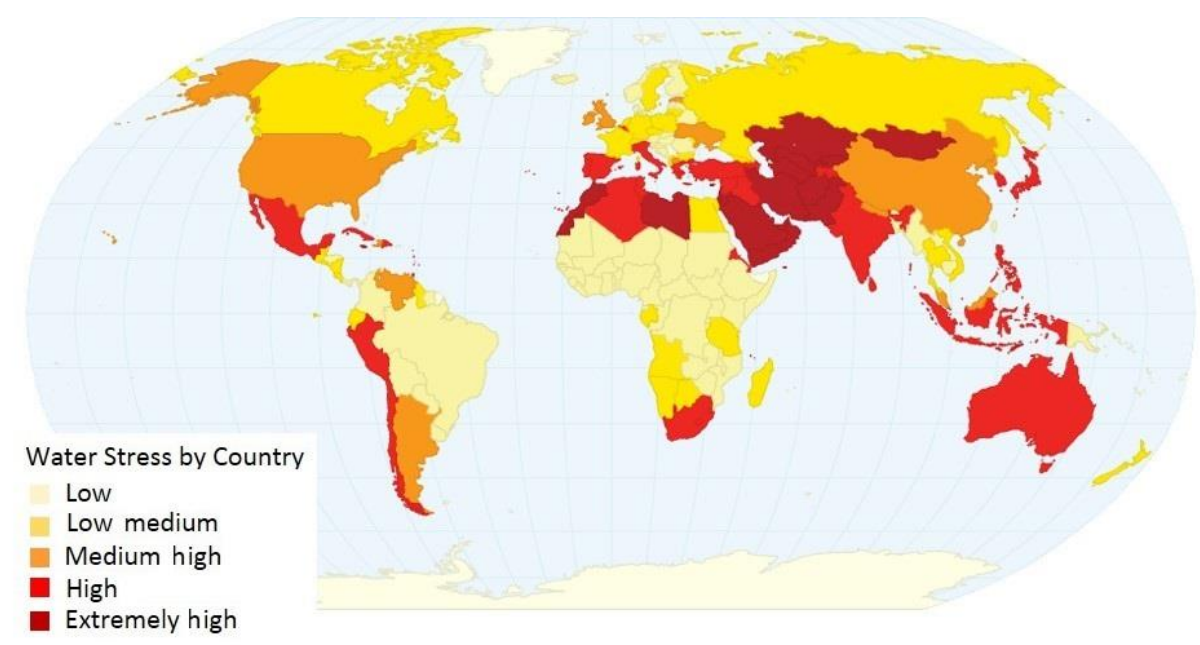

Figure 1: Projected increase in global water stress by 2025

Source: adapted from World Resources Institute (2013) 

supply is through the treatment of saline water.

Desalination is the process of removing salt from saline sources, and is a technologically feasible process to provide safe drinking water. Effective treatment of saline sources can more than double the volume of fresh water available in places like India. ${ }^{3}$ It is true that in the past high costs, high energy needs, possible environmental harm and often high maintenance requirements have made desalination an unattractive option of last resort for most populations. However, it has been demonstrated by several countries faced with severe water stress (e.g. Israel, UAE, Qatar, Saudi Arabia, Egypt) as a viable option for bringing relief to millions of people. Israel, for example, once classified as a water-stressed country, now meets $55 \%$ of its domestic water needs via desalination and has a surplus of fresh water. ${ }^{4}$

To date, many reviews have been written on the technical state of various desalination technologies; however, little work has been done to help guide project implementers on which technologies should be further pursued.

\section{This document aims to fill this knowledge gap by exploring the viability, appropriateness and sustainability of existing and emerging desalination technologies for low-income communities in South and Southeast Asia.}

The objective of this document is to provide a 'desalination road map' for South and Southeast Asia, which:

- provides a fundamental overview of desalination and evaluates different technologies based on their energy consumption and cost;

- identifies the best available desalination technologies that can provide 1-10 cubic metres $\left(\mathrm{m}^{3}\right)$ per day of drinking water from brackish water sources with total dissolved solids (TDS) of between 1,000 and 10,000 parts per million (ppm);

- discusses lessons learned from previous projects that have introduced desalination technology into low-income or remote communities;

- identifies potential partners in suppliers of desalination technologies and NGOs and social enterprises for the future introduction of low-cost, energy-efficient desalination technologies. 
To do this, the report is divided into four sections.

Section 1: Introduces major and emerging desalination technologies from a fundamental scientific perspective and provides a quick comparison between technologies based on their appropriateness for small communities in South and Southeast Asia.

Section 2: Provides a detailed comparison of the main commercially available desalination technologies based on their energy consumption and financial costs, and evaluates the practicality of bringing these technologies to the field.

Section 3: Explores case studies of past and current desalination facilities and gives a brief description of successes, failures and lessons learned.

Section 4: Conclusion and recommendations. The conclusion evaluates existing desalination technologies according to their appropriateness and sustainability in low-income and remote locations, complete with a decision guide to help identify critical intersections that will be useful to consider when designing, installing and maintaining desalination facilities in South and Southeast Asia.

Appendix: Provides a list of potential partners to collaborate with for the installation and operation of desalination facilities, including technology suppliers, NGOs, and social enterprises. 


\section{OVERVIEW OF DESALINATION TECHNOLOGIES}

1.1 SALINE WATER SOURCES

Before evaluating the different types of desalination technologies, it is important to briefly discuss the salt content of water, referred to as its salinity, and how it is measured. The salinity of any water source is often described in terms of its total dissolved solids (TDS), which has units of milligrams per litre $(\mathrm{mg} / \mathrm{L})$ or parts per million $(\mathrm{ppm})$. As defined by WHO, 'Total dissolved solids (TDS) is the term used to describe the inorganic salts and small amounts of organic matter present in solution in water. The principal constituents are usually calcium, magnesium, sodium, and potassium cations and carbonate, hydrogen carbonate, chloride, sulfate, and nitrate anions. ${ }^{5}$ Salinity is estimated through electrical conductivity measurements and hence is usually reported in units of $\mu \mathrm{S} / \mathrm{cm}$, but this report discusses salinity as TDS in units of ppm.

Saline water sources are broadly divided into three categories:

brackish, sea/ocean and brine.

Brackish water ranges between 1,000 and $35,000 \mathrm{ppm}$, sea/ocean water is on average $35,000 \mathrm{ppm}$ and brine is anything greater than 35,000 ppm. Table $2^{6}$ gives a breakdown of these three main categories along with various sub-categories. ${ }^{7}$ For a sense of scale, the salinity of human blood is $9,000 \mathrm{ppm}$.

Table 2: Classification of water sources based on salinity

\begin{tabular}{|l|r|}
\hline Water source & TDS $\mathbf{( m g / L ~ = ~ p p m ) ~}$ \\
\hline Excellent to good & $300-600$ \\
\hline Potable water & $<1,000$ \\
\hline Mildly brackish & $1,000-5,000$ \\
\hline Moderately brackish & $5,000-15,000$ \\
\hline Heavily brackish & $15,000-35,000$ \\
\hline Average sea/ocean water & 35,000 \\
\hline Brine & $>35,000$ \\
\hline
\end{tabular}

Source: adapted from U.S Bureau of Reclamation (2003)

In 2003, WHO measured the palatability of drinking water based on a taste test and sorted responses into five categories: excellent - less than 300 ppm; good - between 300 and 600 ppm; fair - between 600 and 900 ppm; poor - between 900 and 1,200 ppm; and unacceptable greater than $1,200 \mathrm{ppm}^{8}$

Consuming saline water sources can do more harm than good to humans. At greater than 9,000 ppm, saline water tries to achieve osmotic balance with the blood, causing blood cells to lose water and leaving the body dehydrated. ${ }^{9}$ Another problem with the consumption of saline water is increased sodium intake, leading to hypertension (high blood pressure). In 2011, a study done in Bangladesh found that an increase in hypertension among pregnant women correlated with increased salt intrusion into their groundwater supplies (drinking water source).$^{10}$ While the full extent of health effects from drinking saline sources is not well established in the literature, based on the sensitivity of plant and animal life to increased salinity, it is safe to assume that saline sources must be adequately treated prior to consumption.

That said, having some dissolved solids in drinking water is important. Drinking highly purified water with very low TDS can be unpalatable. More importantly, consuming demineralized water 
can cause health problems associated with insufficient amounts of the sodium, calcium and magnesium needed for basic health. However, the fourth edition of WHO's Guidelines for Drinking-water Quality (2011) reported that there is insufficient data on the exact health effects of consuming low salt, so it did not provide minimum value guidelines. ${ }^{11}$

As a general reference, $300-600$ ppm is a desirable and safe salinity range for drinking water.

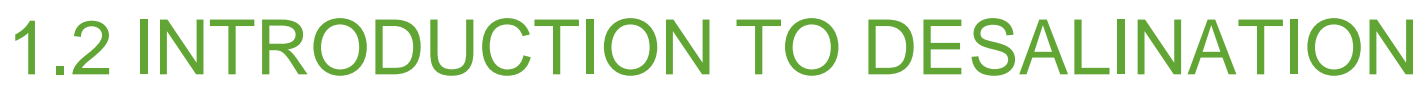

The basic process of desalination is to take a saline water source and invest energy to output two separate streams, a stream of salt-free fresh water and a stream of salty brine (Figure 2). An efficient and desirable desalination technology uses a minimal amount of energy to produce a large volume of fresh water and a very small volume of highly concentrated brine.

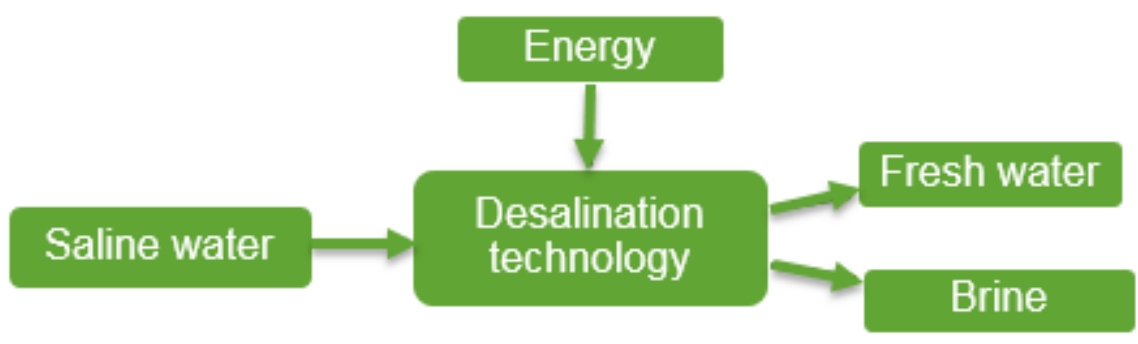

Figure 2: The desalination process

Energy is used to power technologies that separate salt water into fresh water and waste brine

Available desalination technologies can be broadly classified into three main categories based on the fundamental physical and chemical principles governing the saline water separation process: 1) thermal methods; 2) membrane-based processes; and 3) charge-based separation techniques. Thermal methods rely on phase change: thermal energy is used to evaporate water (leaving salt behind) and then the water vapour is condensed to collect fresh water. Membrane desalination processes physically separate salt from water using differences in osmotic (chemical) potentials across a semi-permeable polymer membrane. Charge-based separation techniques take advantage of the fact that salt is comprised of charged ions, which can be separated from water by simply applying a small electric potential.

In general, thermal technologies are most effective at large capacities $\left(>3,000 \mathrm{~m}^{3} /\right.$ day $)$ while charge-based separation technologies are best suited for smaller operations $\left(\sim 250 \mathrm{~m}^{3} /\right.$ day). Membrane desalination methods have been optimized and commercialized for a range of capacities, from very large-scale industrial use $\left(190,000 \mathrm{~m}^{3} /\right.$ day $)$ to small-scale $\left(0.075 \mathrm{~m}^{3} /\right.$ day $)$ inhome applications. ${ }^{12}$ 


\subsection{DESALINATION TECHNOLOGIES}

\subsubsection{Thermal desalination technologies}

Thermal desalination technologies were the first desalination systems to be commercialized. A major reason for this is the simplicity of the basic principle, which people have observed for centuries. Thermal technologies use heat energy to induce phase changes so that the saline water is evaporated and then condensed to produce fresh water.

The boiling temperature of water increases with the salinity of the source. However, compared with the large amount of energy required to heat water, the additional energy required for boiling brackish water compared with seawater is negligible. This means that, for all practical purposes, the energy required for desalination via thermal processes does not vary significantly between brackish and seawater sources.

\section{Hence, from a cost standpoint, thermal technologies are a better choice for desalination of higher-salinity than lower-salinity sources. ${ }^{13}$}

There are several different commercially available thermal technologies, but the three most widely used are multiple-effect distillation (MED), multi-stage flash distillation (MSF) and vapour compression distillation (VCD).

\section{Typically, MED, MSF and VCD are only cost-effective at capacities above $3,000 \mathrm{~m}^{3} /$ day, and are ideal for desalination of higher-salinity sources $(\geq 35,000 \text { ppm })^{14}$}

All commercial thermal technologies must include efficient and effective heat exchange mechanisms to be viable.

There are various new and emerging thermal technologies (e.g. solar still distillation, adsorption distillation and membrane distillation) that are designed and optimized for small to mid-size operations (10-10,000 litres per day (L/day)). These technologies operate under the same basic principle as the technologies described above but, based on their specific design, differ in energy use, water recovery rate, cost, simplicity of operation, and so on.

\section{Multiple-effect distillation (MED)}

Adopted from the chemical industry in the early 1900s, MED is a multi-step thermal desalination process. In MED, feed water is sprayed onto heated tubes carrying steam to generate vapour. The vapour produced is collected and used as a heat source in the subsequent stage while brine is collected at the bottom of the chamber. The vapour from stage one is used as steam for evaporating feed water in stage two, and similarly vapour from stage two is used for heating in stage three. The chamber pressure is progressively reduced as the feed water moves through the system, so less heat is needed for evaporation. In the final stage, the steam is condensed using a heat exchanger cooled by seawater. The stages in MED are referred to as 'effects' and a typical process plant can contain up to 20 effects. MED plants are usually built for capacities of between 2,000 and $10,000 \mathrm{~m}^{3} /$ day, with a maximum operating temperature of $70^{\circ} \mathrm{C} .{ }^{15}$ 


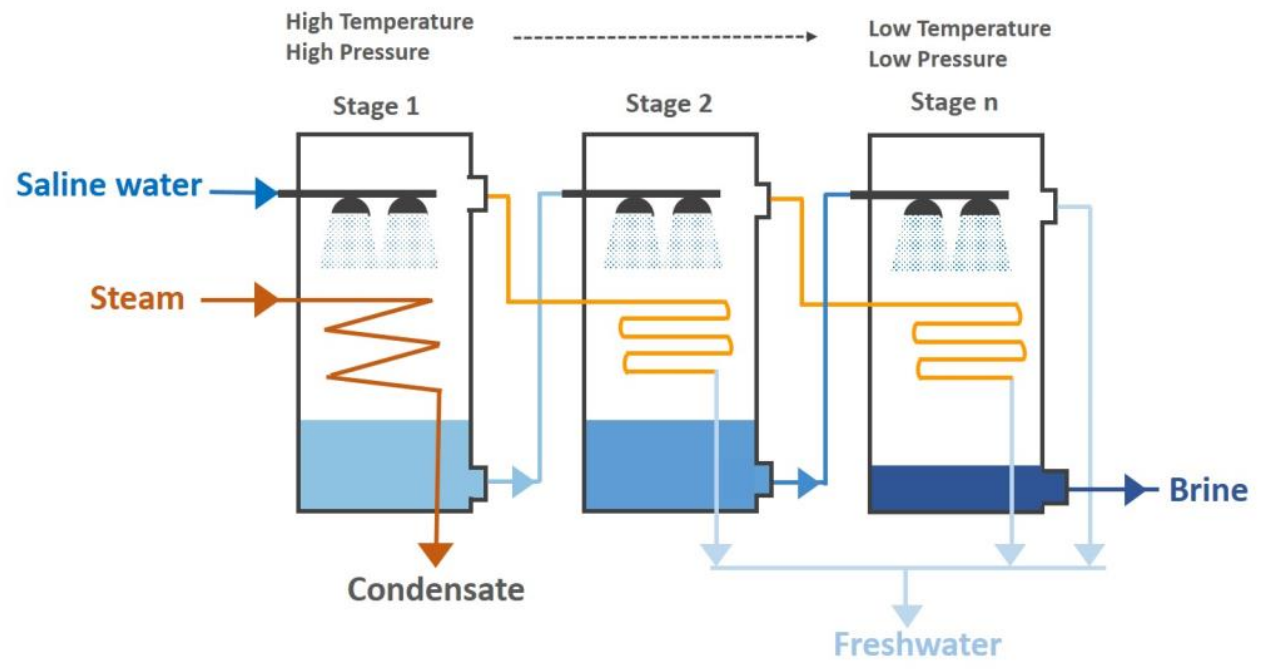

Figure 3: Schematic of MED technology

Water is separated from salt via steam-induced evaporation. The steam produced from an earlier stage is used to heat the next stage, all the while separating fresh water from concentrated waste brine.

Source: adapted from http://www.separationprocesses.com/Distillation/DT Chp07b.htm

Although the first large-scale MED plant was in operation (in Saudi Arabia) as early as 1930, the popularity of the technique has since declined. This is in part due to the high energy needs of thermal methods in comparison with membrane-based technologies, but also due to challenges specific to MED in identifying suitable materials to minimize corrosion and associated maintenance. ${ }^{16}$

\section{Multi-stage flash distillation (MSF)}

Invented in 1950 by Robert Silver, MSF is a distillation process similar to MED and is conducted over multiple stages. It takes advantage of the fact that evaporation happens when the vapour pressure is equal to the external pressure in the chamber. Thus, by initially heating water in a high-pressure environment and then progressively reducing the pressure, evaporation can be stimulated at successively lower pressures and temperatures. A detailed description of each stage of MSF is as follows: first cold feed water passes through each chamber before reaching the pressure boiler. This allows the cold feed water to act as a coolant and assist condensation of the vapour at no extra cost, while simultaneously recovering some of the heat from the vapour. The feed water is then heated in the boiler at high pressure and fed into the first chamber at a lower pressure such that it 'flash evaporates'. The water vapour is condensed by the cold feed water and collected in a separate tubing system inside the chamber. The fresh water collected, as well as the brine, then enters the next chamber. In this second stage, the brine experiences a drop in pressure to aid further evaporation while the fresh water remains cool and is collected in dedicated tubes for further condensation and collection. The process continues on in multiple stages, with the pressure successively decreasing. The final result is desalinated fresh water and concentrated brine. ${ }^{17}$

MSF facilities have been optimized for large-scale operation and on average require 23-27 kilowatt hours $(\mathrm{kWh}) / \mathrm{m}^{3}$ of seawater treated. ${ }^{18}$ To reduce energy costs, MSF plants can be co- 
located with power plants and the waste heat from power generation used as the initial heat source for MSF.

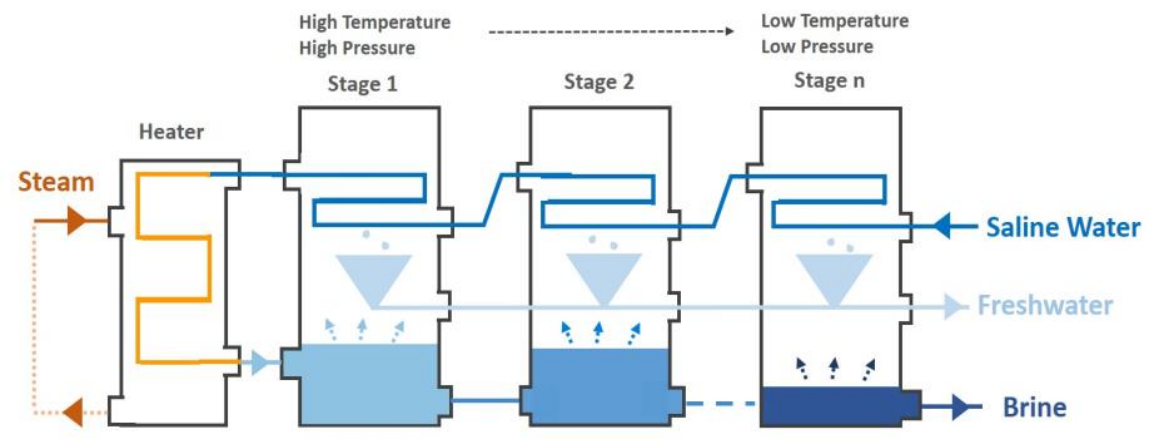

Figure 4: Schematic of MSF technology

Water is separated from salt via flash evaporation. The water vapour condenses on the cool salt water feed pipes, producing fresh drinking water and leaving behind waste brine.

Source: adapted from https://sites.google.com/site/kjdesalination/vacuum-distillation

\section{Vapour compression distillation (VCD)}

The feature distinguishing VCD from MED and MSF is that the heat transfer needed for evaporation comes from the compression of the evaporated water vapour instead of direct exchange from steam produced in a boiler. The basic principle is that, by applying pressure to the water vapour produced from the initial feed water, its temperature is increased and more feed water will evaporate and condense (Figure 5). There can also be an additional heat source to further encourage evaporation of the concentrated brine collected at the bottom of the system. It is possible to use VCD in conjunction with MED or by itself, depending on how the water treatment plant is designed. In general, VCD plants are smaller in size and have lower capital costs compared with MED and MSF, but they have higher maintenance needs due to the use of pumps and compressors. ${ }^{19}$

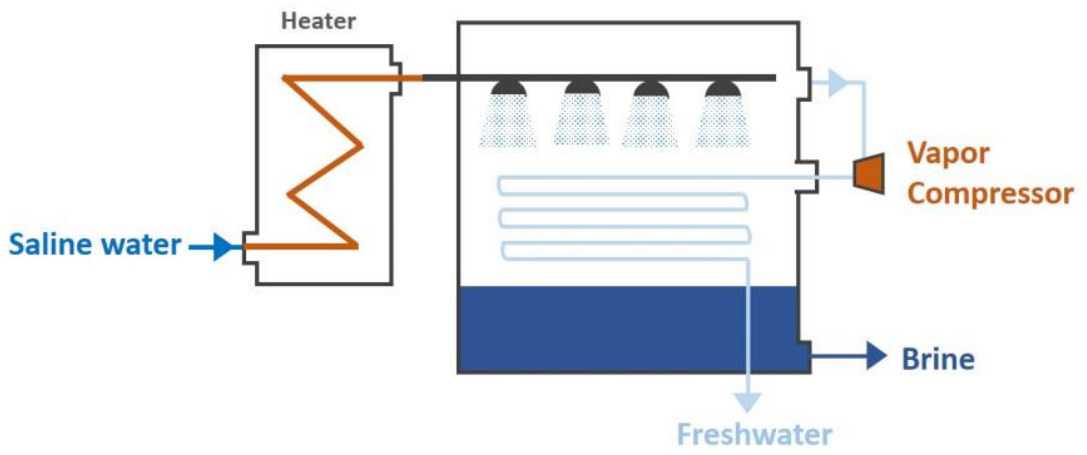

Figure 5: Schematic of VCD technology

Water is separated from salt using a vapour compressor to enhance evaporation rates. The compressed vapour is eventually cooled to become fresh water and the salty brine is collected separately.

Source: adapted from https://sites.google.com/site/kjdesalination/vacuum-distillation 


\section{Solar still distillation (SSD)}

SSD technologies use the sun as the heat source for evaporation. Saline water is evaporated in a large sealed basin, whose size is determined by the desired fresh water output. The vapour condenses as fresh water on the underside of the basin's cover, which is sloped so that the water moves down it into a collection trough (Figure 6). The fresh water is then stored in a tank, to be used and distributed as necessary. The design of SSD units is quite simple and as a result they are much more common in rural settings than other thermal technologies (MSF, MED or VCD).

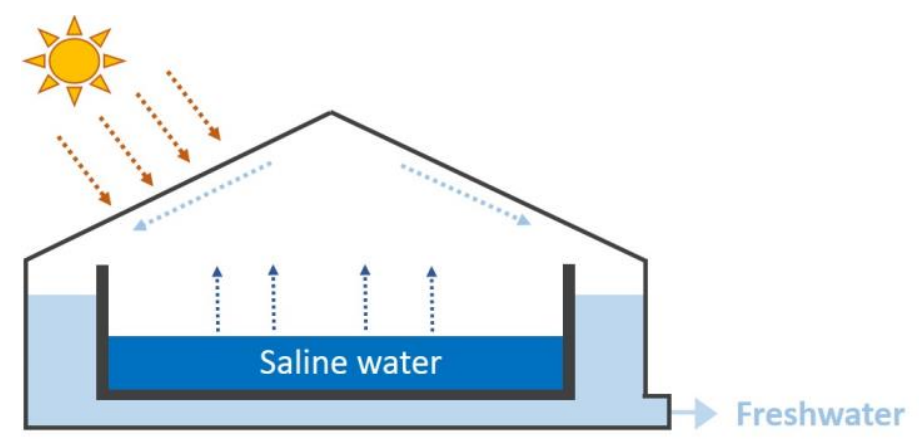

Figure 6: Schematic of SSD technology

Saline water is evaporated directly by the heat of the sun and condenses in a separate fresh water catchment. Source: adapted from Mechell and Lesikar (2014)

Its mechanistic simplicity and ease of installation have made SSD attractive to users. However, the productivity of SSD units is generally quite low and is affected by seasonal variations, making them less practical even on a small scale. ${ }^{20}$ The daily productivity of SSD is typically measured in water output per square metre $\left(\mathrm{m}^{2}\right)$ of solar still. A simple passive SSD system produces 2$5 \mathrm{~L} / \mathrm{m}^{2} /$ day and a modified system optimized for maximal output around $30 \mathrm{~L} / \mathrm{m}^{2} /$ day. ${ }^{21}$ Assuming a realistic production of $4 \mathrm{~L} / \mathrm{m}^{2} /$ day, a school with 3,000 students, requiring $10 \mathrm{~L} /$ day/student, would need an SSD unit covering an area equivalent to that of a football field. Not only is this a lot of space, but solar stills are often priced per unit and to buy a football field's worth would cost tens of thousands of dollars.

\section{If SSD is pursued as a desalination option, it is important that its low water output and consequent large land requirements and high capital cost are carefully considered.}

While certain communities in arid regions may have a large open land area available, for most parts of densely populated South Asia the land requirements of SSD are a constraint. For these reasons, Oxfam recommends SSD for single households and not for community-scale installations. However, SSD technology can be used for desalination of both seawater and brackish water sources. 


\section{Other emerging thermal technologies}

\section{Adsorption desalination}

Adsorption desalination $(A D)$ utilizes low-grade heat $\left(75-90^{\circ} \mathrm{C}\right)$ to evaporate saline or brackish water, which is then adsorbed onto an adsorbent matrix (i.e. it collects on the surface). The adsorbed water is subsequently desorbed from the matrix using low-grade waste heat, followed by condensation of the desorbed vapour to produce fresh water. A variety of adsorbents have been reported in the literature (activated alumina, silica gel and molecular sieves) and tested in AD systems. The key to identifying the best adsorbent material is matching the regeneration temperature of the adsorbent to the temperature of the waste heat source..$^{22}$

Benefits of AD include the use of low-grade waste heat, lower maintenance costs from reduced fouling and corrosion and the ability to treat water sources containing high concentrations of organics. The technology has been demonstrated at pilot scale using inexpensive silica gel adsorbents. However, the need to couple AD systems with waste heat sources and optimizing the type of adsorbent to the specific heat source temperature are factors limiting widespread adoption of the technology.

\section{Membrane distillation}

Membrane distillation (MD) is a thermal desalination process where saline water is heated to generate water vapour that is then passed through a porous membrane. The membrane is hydrophobic, allowing water vapour but not liquid water to pass through. The process is driven by the difference in vapour pressure resulting from the difference in temperature on the two sides of the membrane. ${ }^{23}$ The process uses low-grade thermal energy to produce the water vapour. ${ }^{24}$ Besides desalination, MD is also being developed for wastewater treatment and food processing applications.

Benefits of MD include high-quality distillate produced at relatively low temperatures $\left(<100^{\circ} \mathrm{C}\right)$, reduced pre-treatment requirements compared with pressure-based membrane processes and the use of low-grade heat (solar or waste heat) for operation. ${ }^{25}$ Similar to other technologies that use membranes, MD has the disadvantage of membrane fouling (which is discussed in greater detail in the next section). In general, MD is in the early stages of development and further research is required to evaluate its energy needs and performance under varying operational conditions. ${ }^{26}$

\section{Thermal desalination technologies: summary}

In all thermal desalination technologies - MSF, MED and VCD - the energy required for desalination is not significantly affected by the salinity of the raw water, which makes the energy needs for treatment of lower-salinity brackish water similar to those for much more saline seawater. Therefore, from the perspective of energy use, thermal technologies are best suited for seawater desalination. In general, however, thermal technologies require energy in the range of $23-25 \mathrm{kWh} / \mathrm{m}^{3}$ and are used only at large scales; thus they are not ideal for small rural communities in South Asia interested in low-cost, low-energy treatment of brackish water $(3,000-10,000 \mathrm{ppm})$. For this reason, none of the major thermal technologies are discussed further in this report. 
SSD gets its energy directly from the sun and thus the large energy requirement is not as great a concern. However, SSD has the disadvantages of low daily productivity and high land requirements, which often makes it impractical for community-scale use. Despite these considerations, SSD is explored further in this report because it is viable on a household scale, is simple to operate, is powered completely by the sun and has been successfully demonstrated in the past.

\subsubsection{Membrane desalination technologies}

Membrane technologies use a thin film of semi-permeable material to physically separate salt from water. Membranes can be made from a variety of materials, including synthetic polymers (e.g. cellulose acetate, polyamide), ceramics, metals and composites. In general, desirable properties of a desalination membrane include high porosity, uniform pore size, good mechanical strength, flexibility, pH stability, hydrophilic character, chemical robustness (tolerance to chlorine) and low cost. ${ }^{27}$ Synthetic polymeric membranes meet most of these criteria, and are the primary material used for desalination applications today. While cellulose acetate membranes were widely used in the early days of desalination, most systems now use polyamide-based thin film composite membranes. ${ }^{28}$

Although membrane-based desalination technologies have been successfully demonstrated at large scale and for treatment of both low- and high-salinity water sources, the processes are generally energy-intensive and suffer from issues of membrane fouling. ${ }^{29}$ The challenges with fouling add considerable operational complications in terms of pre- and post-treatment requirements, adding to the overall cost of the process.

\section{Reverse osmosis (RO)}

Osmosis refers to the natural movement of water molecules across a semi-permeable membrane from a region of low salt concentration to one of high salt concentration, with the purpose of balancing the salt concentration on either side. The force per area that drives this movement is defined as the osmotic pressure. In reverse osmosis (RO), an external pressure greater than the osmotic pressure is applied to the side with higher salinity. This forces water across the membrane, resulting in highly concentrated brine and fresh water (Figure 7). The pressure required for $\mathrm{RO}$ is dependent on the salinity of the feed water; for brackish water, values range between 150 and 450 psi (around 10-31 bar), while for seawater they can rise to 1,200 psi (83 bar). ${ }^{30}$

\section{Reverse osmosis has been developed and widely commercialized over the} past $\mathbf{5 0}$ years, and is by far the most prevalent desalination technology in use worldwide today. In 2013 , RO was responsible for $71 \%$ of the world's fresh water supply produced by desalination. ${ }^{31}$ 


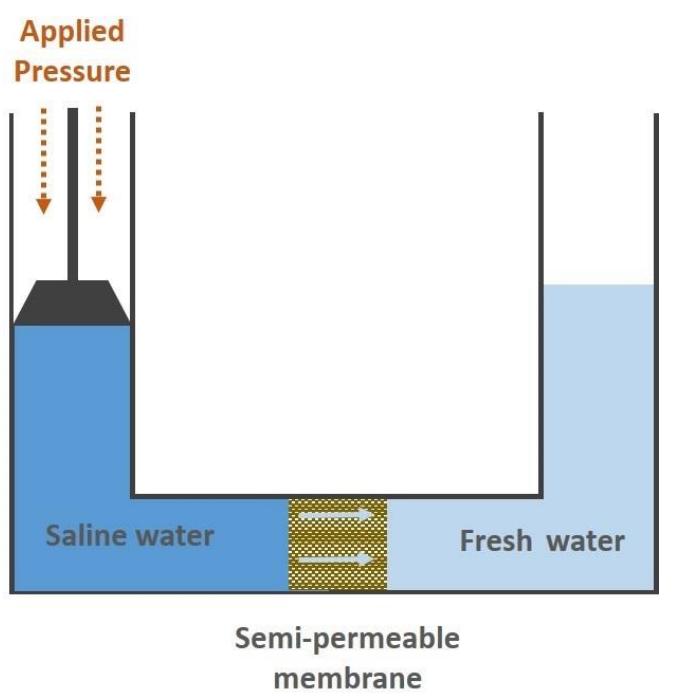

Figure 7: Schematic of RO technology

An externally applied pressure pushes fresh water through a semi-permeable membrane and leaves behind waste brine. Source: adapted from Elimelech (2011)

The largest RO desalination plant in the world is in Sorek, Israel; it is capable of producing $627,000 \mathrm{~m}^{3} /$ day, at a reasonable price of $\$ 0.58 / \mathrm{m}^{3}$. This single plant supplies $20 \%$ of Israel's household water needs. ${ }^{32}$ The prevalence of $\mathrm{RO}$ makes it easy to find local distributors, replacement parts and partners willing to help install, operate and maintain systems. $R O$ is a wellresearched technology that has achieved economies of scale, leading to significantly reduced initial capital costs and minimal risks (this is explored further in section 2). However, RO still faces three key challenges: high energy use for brackish water treatment, low water recovery rates and membrane fouling.

High energy use for treatment of brackish water

In comparison with other technologies, specifically charge-based separation technologies, $\mathrm{RO}$ can be between $30 \%$ and $75 \%$ more energy-intensive for the treatment of mildly brackish water (TDS $<3,500$ ppm). ${ }^{33}$ However, energy consumption in RO has been optimized over the past 50 years for treatment of higher-salinity seawater sources $(35,000 \mathrm{ppm})$, and it is far more energyefficient than charge-based separation technologies for higher salinities. ${ }^{34}$ This is discussed in greater detail in section 2 .

\section{Low water recovery rate}

A single-pass $\mathrm{RO}$ system, which passes the saline water through the membranes once only, is likely to recover just $25-50 \%$ of the water. ${ }^{35}$ This means that for every 100 litres of saline water that are fed into the system only 25-50 litres of fresh water are produced and 50-75 litres are discarded as waste brine. This low water recovery rate is an issue in particular for inland communities using $\mathrm{RO}$ for brackish water that have a limited supply of raw water source and are trying to conserve water and/or do not have a safe way (for people or the environment) to dispose of the waste brine. This is not so much of a concern for coastal communities, because the ocean is a vast source and small amounts of brine can be safely disposed of in the sea. 
RO water recovery can be increased by recirculating the brine through additional membranes. This process, referred to as multi-pass $\mathrm{RO}$, can increase water recovery from as low as $25 \%$ to as high as $80 \%$ in commercially available units. ${ }^{36}$ However, a multi-pass $\mathrm{RO}$ system requires higher capital investment for additional membranes and related infrastructure. Further, the multiple passes add considerably to energy use, as well as to other operational expenses such as membrane cleaning. The higher capital and operating costs of a multi-pass RO system may only be worth it if there is a shortage of source water or there is no easy, cheap or safe way to dispose of waste brine. For communities looking for inexpensive RO systems, multi-pass RO may simply be too expensive. Here it is worth noting that new membrane modules are being tested in the United States to achieve high water recovery rates, similar to those obtained with multi-pass RO but using just a single-pass system. A high-recovery, single-pass $R O$ system would have clear benefits over multi-pass $R O$. However, significant research and development (R\&D) remains to be done before the technology is commercially available and is sufficiently inexpensive for widespread use.

\section{Fouling}

A major hindrance for $\mathrm{RO}$ at any scale is membrane fouling. Fouling occurs when microbes, chemical species and other suspended particles clog the small-diameter pores (0.1-1 nanometre $(\mathrm{nm})$ ) of the membrane..$^{37}$ Fouling degrades the overall performance of $\mathrm{RO}$, requiring regular maintenance and therefore increasing cost. There is a lot of research in progress investigating how to reduce fouling. Currently, extensive pre-treatment is used to minimize fouling by removing both biological and chemical foulants from the source water. A common and relatively cheap way to deal with fouling of membranes is to clean them regularly with a low concentration of acid. In general, though, the pre-treatment and cleaning necessary for RO results in increased operating expenses and risks of failure that can threaten the long-term sustainable operation of facilities in small communities.

\section{Forward osmosis (FO)}

Forward osmosis is an emerging membrane-based desalination technology that relies on natural osmotic pressure to separate salt and water. The osmotic pressure difference between the saline water on one side of the membrane and a highly-concentrated draw solution on the other leads to the flow of water molecules across the semi-permeable membrane. In a subsequent step, the water is separated from the draw solute using thermal energy. ${ }^{38}$

Unlike RO, FO does not require high-pressure pumping, which allows for the use of thinner membranes in the system. The lower-pressure operations also minimize membrane fouling and clogging compared with $\mathrm{RO}$. For these reasons, $\mathrm{FO}$ is often advertised as a much lower-energy desalination method compared with $\mathrm{RO}$. However, the energy and resources required to recover fresh water from the draw solute often outweigh the energy saved from pumping, resulting in comparable operational costs overall. More importantly, the health risk of residual draw solute in the freshwater product is a concern that currently prevents the use of FO for the treatment of drinking water. However, with further R\&D and with new draw solutes, FO may be a viable option in the future. 


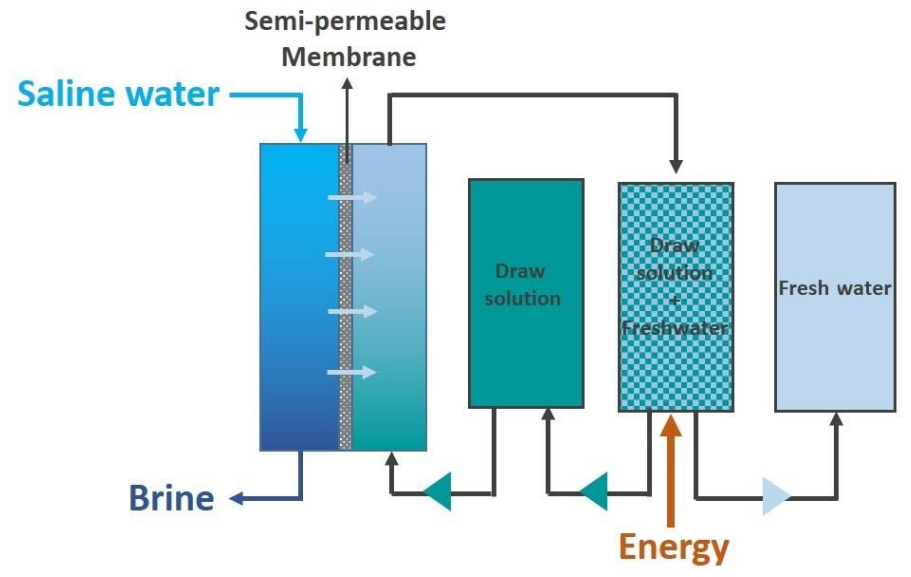

Figure 8: Schematic of FO technology

A draw solution is used to osmotically push fresh water across a semi-permeable membrane and leave behind waste brine. In the second step, energy is used to separate the draw solution from the fresh water. Source: adapted from Schiermeier (2008)

\section{Membrane desalination technologies: summary}

It is possible that, with additional research, forward osmosis could be an attractive and competitive desalination option. However, currently FO is in the early stages of development, and concerns with the safety of draw solutes to produce drinking water make it a non-option for communities in South and Southeast Asia. Hence, FO is not considered further in this report.

Reverse osmosis, on the other hand, is the most commonly available desalination technology worldwide and has been commercialized at the household, community and industrial scales. The prevalence of $\mathrm{RO}$ makes it easy for communities to find local distributors, replacement parts and partners willing to help install, operate and maintain facilities. Having been optimized and commercialized for decades, $\mathrm{RO}$ technology is relatively inexpensive and lowrisk. A detailed discussion of the technical and economic considerations of $\mathrm{RO}$ is included in the following sections. Overall, RO is a very promising option for desalination facilities in South and Southeast Asia producing 1-10 $\mathrm{m}^{3} /$ day, especially for coastal communities treating seawater. 


\subsubsection{Charge-based desalination technologies}

Charge-based separation technologies take advantage of electrostatic attraction and repulsion to separate out positively charged sodium $\left(\mathrm{Na}^{+}\right)$and negatively charged chloride $(\mathrm{Cl})$ ions (as well as other salt ions) from water. This is often done by applying a small voltage across two pieces of metal -electrodes - placed in saline water. The $\mathrm{Na}^{+}$ions are attracted to the negative electrode (cathode), and the $\mathrm{Cl}^{-}$ions to the positive electrode (anode). More details about the process are included in the explanations of each specific technology.

Charge-based technologies are ideal for low-salinity brackish sources. The reason for this is that, unlike RO and all thermal processes, charged-based technologies desalinate water by capturing the salt out of the saline source, instead of selectively removing the water molecules. Thus, for charged-based technologies, the more salt in solution the more energy required to remove it, or to put it another way, energy use scales with source salinity. RO and thermal technologies are less dependent on source water salinity and thus more energy-efficient for high-salinity sources (for more details on this, see Figure 14 below). Charge-based technologies tend to have higher water recovery rates (85-90\%) than either RO (25-80\%) or typical thermal technologies (35\%). ${ }^{39}$ The most technologically advanced and widely available for purchase charge-based separation technologies are electrodialysis (ED), electrodialysis reversal (EDR) and membrane capacitive deionization $(\mathrm{mCDI})$. Note that sometimes these technologies are classified as membrane technologies because of the presence of ion-selective membranes. This report finds chargedbased separation to be a more descriptive classification because it builds on the fundamental operating principle of the technology instead of its physical components.

Although theory suggests charge-based separation as more energy-efficient for sources up to $5000 \mathrm{ppm}$, in practice this salinity max will be considerably lower. Commercial mCDI and EDR systems have thus far only been demonstrated for feed waters of very slow salinities (<3500ppm).

\section{Electrodialysis and electrodialysis reversal (ED/EDR)}

Electrodialysis separates salts from water by using an applied voltage and ion-selective membranes. An ED unit is a series of parallel cells composed of alternating membranes for the selective transport of positively charged ions (cations) and negatively charged ions (anions), bounded by two electrodes (Figure 9). The electrodes are typically made of titanium (Ti) and are connected to a direct current (DC) power source such that one plate carries a positive charge and the other carries a negative charge. The membranes, which form the parallel cells within the larger ED unit, are ion-selective. Cation exchange membranes (CEMs) are designed chemically to allow only cations to pass through easily, while being a barrier to anions. Conversely, anion exchange membranes (AEMs) selectively allow anions to pass through while blocking cations. The result is that salty brine and fresh water are collected in alternating compartments of the ED unit. Although both an external voltage and ion-selective membranes are important for charge separation, the driving force in ED is the applied voltage across the anode and cathode. ${ }^{40}$

Over time salts and organics will accumulate on the membrane surfaces, just like fouling in $\mathrm{RO}$ membranes. By reversing the polarity of the applied voltage, the salts and organics are driven off the membranes and back into solution. This essentially 'cleans' the membranes, increasing the effectiveness and longevity of the unit. An ED system with the ability to reverse polarity is known 
as an electrodialysis reversal (EDR) system. Once the membranes are close to their original performance standards, the voltage polarity is reversed for salt removal as before.

ED and EDR can also be easily adapted to be powered directly by photovoltaics, making them environmentally sustainable and technically feasible for off-grid communities.

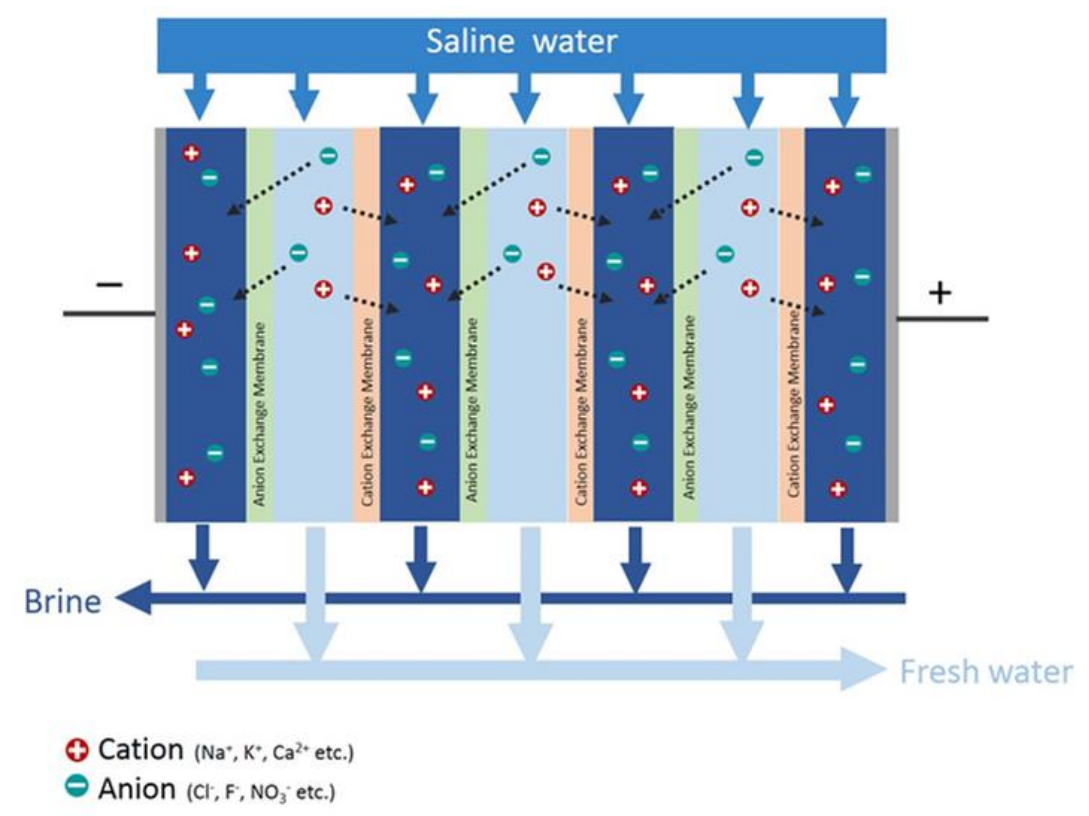

Figure 9: Schematic of ED technology

An externally applied voltage draws salt ions to oppositely charged electrodes. Salt ions are further separated using ion-exchange membranes. What results is alternating streams of fresh water and waste brine.

Source: adapted from http://waterions.aceenvironment.com/edr

\section{Membrane capacitive deionization (mCDI)}

Like ED and EDR, mCDI desalination systems are driven by an external voltage. However, the fundamental salt removal mechanism in $\mathrm{mCDI}$ is capacitive, resulting from the adsorption of ions onto the electrode surface, and is not a membrane-assisted separation as in ED or EDR. There are two stages in mCDI: 1) electrosorption of the ions onto the electrodes and 2) desorption of the ions to 'clean' the electrode surface. ${ }^{41}$ During the first stage a voltage is applied across two porous carbon electrodes, attracting oppositely charged ions to the respective electrode. The ions stay immobilized while water flows through the system, producing fresh water. Eventually the electrodes reach capacity and can no longer adsorb salt ions and must be regenerated. This is accomplished by turning off or reversing the applied voltage, which causes the captured ions to desorb from the electrode surface and return to solution. The water flowing through the system during regeneration is highly concentrated brine. Once the electrodes have been regenerated, the original voltage is applied and the process is repeated until the desired volume of fresh water is produced. 
The membranes in $\mathrm{mCDI}$ are used mainly to increase the energy efficiency of the process by preventing unintended ion transfer from one electrode to the other during regeneration. Although the membranes are placed directly on the electrode, they are prone to fouling like all the other technologies that use membranes..$^{42} \mathrm{mCDI}$ is based on inexpensive materials, requires low levels of maintenance and has high water recovery rates (typically between $80 \%$ and $95 \%$ ), making it a very promising technology. The challenge for $\mathrm{mCDI}$ currently is that it is not as widely commercialized as RO. However, there is a lot of potential for $\mathrm{mCDI}$ to break into the small-scale brackish water ( $<3,500 \mathrm{ppm})$ desalination market. ${ }^{43} \mathrm{~A}$ number of companies in South Asia (notably AquaSphere and InnoDI) are currently working to realize the potential of $\mathrm{mCDI}$ technology through widespread commercialization and local manufacturing efforts, which bring down the capital cost and increase adoption of these technologies (for more on individual suppliers, see Appendix).

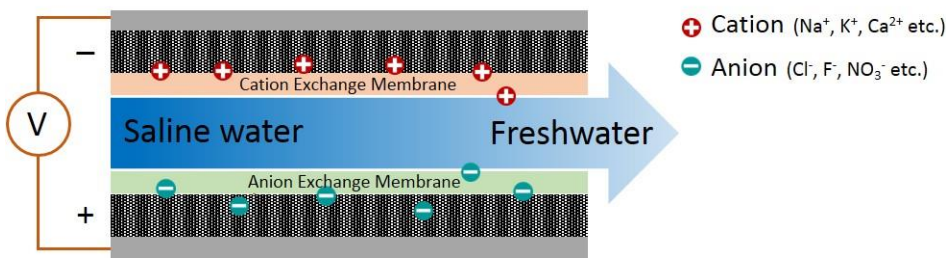

Figure 10: Schematic of mCDI technology

First, an externally applied voltage attracts and adsorbs salt ions to produce a fresh water stream, then the applied voltage is reversed and the salt ions are rejected into a waste brine (this second stage is not shown in the figure). Source: adapted from Biesheuvel and van der Wal (2010)

\section{Charge-based desalination technologies: summary}

Charge-based desalination technologies - electrodialysis, electrodialysis reversal and membrane capacitive deionization - have recovery rates of between $80 \%$ and $95 \%$ while reverse osmosis offers only up to $80 \%$, even with a multi-pass system (single-pass systems will be closer to $50 \%$ ). Therefore, for inland communities that need solutions for saline groundwater with high water recovery rates, charge-based technologies are a good option. Both $\mathrm{mCDI}$ and ED/EDR have potential to be cheaper than RO for the treatment of brackish waters $(<3,500 \mathrm{ppm})$ due to their reduced energy consumption, lower pre-treatment needs and lower-volume brine production (more on this in the next section).

Both $\mathrm{mCDI}$ and EDR use an applied voltage and ion-exchange membranes, but $\mathrm{mCDI}$ is an adsorption-based separation method while EDR is a membrane separation method. In practical terms, what this means for the operation of the technologies is that EDR is run continuously, simultaneously producing a waste stream and a stream of fresh water. mCDI, on the other hand, produces only one stream at a time, first the freshwater stream through ion adsorption and then the waste stream through ion desorption. However, this does not affect the end users of mCDI units as commercial units generally have two cells that are out of sync to provide a continuous freshwater supply. EDR was originally developed for industrial separation processes and is now being redesigned for drinking water treatment. $\mathrm{mCDI}$, on the other hand, has been designed and developed for drinking water treatment and holds promise for becoming widely used in South and Southeast Asia as a brackish water desalination technology. 
Table 3: Brief description and practical considerations for each desalination technology

(Technologies that are focused on in the rest of this report are shown in green)

\begin{tabular}{|c|c|}
\hline \multicolumn{2}{|r|}{ ogies } \\
\hline $\begin{array}{l}\text { Multiple-effect } \\
\text { distillation } \\
\text { (MED) }\end{array}$ & $\begin{array}{l}\text { MED is a multi-step desalination process in which feed water is sprayed onto } \\
\text { steam-heated tubes to generate vapour, which is collected and used as a } \\
\text { heat source in the next step for further evaporation. The process continues } \\
\text { through subsequent stages until sufficient fresh water is produced from the } \\
\text { evaporation process. MED is energy-intensive, and is usually used in facilities } \\
\text { producing at least } 2,000-10,000 \mathrm{~m}^{3} / \text { day. }\end{array}$ \\
\hline $\begin{array}{l}\text { Multi-stage } \\
\text { flash } \\
\text { distillation } \\
\text { (MSF) }\end{array}$ & $\begin{array}{l}\text { Similar to MED, MSF is conducted over multiple stages. In MSF water is } \\
\text { initially heated in a high-pressure environment then, by progressively } \\
\text { reducing the pressure, boiling and evaporation are stimulated at successively } \\
\text { lower temperatures. Eventually the evaporated water is collected as fresh } \\
\text { water and the salt left behind is collected as brine. Like MED, MSF is energy- } \\
\text { intensive }\left(23-27 \mathrm{kWh} / \mathrm{m}^{3}\right) \text {, and is used in large units producing more than } \\
1,000 \mathrm{~m}^{3} / \text { day. }\end{array}$ \\
\hline $\begin{array}{l}\text { Vapour } \\
\text { compression } \\
\text { distillation } \\
\text { (VCD) }\end{array}$ & $\begin{array}{l}\text { The feature that distinguishes VCD from MED and MSF is that the heat } \\
\text { transfer needed for evaporation comes from the compression of the } \\
\text { evaporated water vapour instead of direct exchange from steam produced in } \\
\text { a boiler. By reducing the volume and subsequently increasing the pressure, } \\
\text { the temperature of the vapour is increased and it can be used as a heat } \\
\text { source for further evaporation of the feed water, which is then condensed to } \\
\text { produce fresh water. In general, VCD has high maintenance needs due to its } \\
\text { reliance on large pumps and compressors. }\end{array}$ \\
\hline $\begin{array}{l}\text { Solar still } \\
\text { distillation } \\
\text { (SSD) }\end{array}$ & $\begin{array}{l}\text { Unlike MED, MSF and VCD, SSD uses the sun as the heat source for } \\
\text { evaporation. Fresh water is collected by solar evaporation and condensation } \\
\text { of saline water from a large, sealed basin. Although final water output is in } \\
\text { general quite low, the design is simple and, as a result, SSD facilities are } \\
\text { more common in rural settings than MED, MSF or VCD. }\end{array}$ \\
\hline $\begin{array}{l}\text { Adsorption } \\
\text { desalination } \\
\text { (AD) }\end{array}$ & $\begin{array}{l}\mathrm{AD} \text { is an emerging technology that utilizes low-grade heat }\left(75-90^{\circ} \mathrm{C}\right) \text { to } \\
\text { evaporate saline water, which is then adsorbed onto an adsorbent matrix. The } \\
\text { adsorbed water is subsequently desorbed from the matrix using low-grade } \\
\text { waste heat, followed by condensation to obtain fresh water. The technology is } \\
\text { still in the development stage and is not commercially available. }\end{array}$ \\
\hline $\begin{array}{l}\text { Membrane } \\
\text { distillation } \\
\text { (MD) }\end{array}$ & $\begin{array}{l}\text { MD is an emerging technology that produces fresh water by evaporating } \\
\text { saline water to vapour, which is passed through a porous membrane, cooled } \\
\text { and collected. In general, most work on MD is still taking place in the lab and } \\
\text { the technology is not commercially available. }\end{array}$ \\
\hline
\end{tabular}




\begin{tabular}{|c|c|}
\hline \multicolumn{2}{|c|}{ Membrane technologies } \\
\hline $\begin{array}{l}\text { Reverse } \\
\text { osmosis } \\
\text { (RO) }\end{array}$ & $\begin{array}{l}\text { In } \mathrm{RO} \text {, an applied external pressure greater than the natural osmotic } \\
\text { pressure forces water across a semi-permeable membrane, resulting in } \\
\text { streams of fresh water and highly concentrated brine. RO is the most } \\
\text { common desalination technology, and in } 2013 \text { was responsible for } 71 \% \text { of } \\
\text { all desalinated water worldwide. }\end{array}$ \\
\hline $\begin{array}{l}\text { Forward } \\
\text { osmosis } \\
\text { (FO) }\end{array}$ & $\begin{array}{l}\text { FO is an emerging technology that uses a highly concentrated draw } \\
\text { solution to generate the osmotic pressure necessary to drive water across a } \\
\text { semi-permeable membrane, instead of applying external pressure as in } \\
\text { RO. An additional step is needed to separate the water from the draw } \\
\text { solution. The technology is still in the development stage and is not } \\
\text { commercially available. }\end{array}$ \\
\hline \multicolumn{2}{|c|}{ Charge-based separation } \\
\hline $\begin{array}{l}\text { Electrodialysis/ } \\
\text { electrodialysis } \\
\text { reversal } \\
\text { (ED/EDR) }\end{array}$ & $\begin{array}{l}\text { In electrodialysis, an applied voltage and ion-selective membranes are } \\
\text { used to separate salt ions from fresh water. The ED unit can receive a } \\
\text { basic cleaning by routinely reversing the voltage; the process is then } \\
\text { referred to as electrodialysis reversal. Major benefits of EDRinclude lower } \\
\text { energy use and higher rate of water recovery rates compared with RO for } \\
\text { treating brackish water sources. Both ED and EDR are commercially } \\
\text { available technologies but are optimized for industrial applications and not } \\
\text { drinking water treatment. }\end{array}$ \\
\hline $\begin{array}{l}\text { Membrane } \\
\text { capacitive } \\
\text { deionization } \\
(\mathrm{mCDI})\end{array}$ & $\begin{array}{l}\text { The mCDI process passes saline water between two electrodes with an } \\
\text { externally applied voltage to adsorb salt ions onto the electrodes, thus } \\
\text { creating a freshwater stream. The membranes in mCDI are used to } \\
\text { enhance the energy efficiency of the system but are not fundamentally } \\
\text { essential for operation. Like EDR, mCDI is commercially available and, with } \\
\text { its lower energy use and higher water recovery rates, it can be both cost- } \\
\text { and energy-effective compared with RO for treating low-salinity brackish } \\
\text { water sources. mCDI technology is commercially available and has been } \\
\text { developed for the treatment of low salinity drinking water sources. }\end{array}$ \\
\hline
\end{tabular}




\subsection{DESALINATION WATER TREATMENT}

Having discussed the basics of different desalination technologies, let us consider briefly how these technologies fit into a complete water treatment facility. Figure 11 gives an example of the whole process to convert raw saline water into drinking water. It is likely that the intake and distribution steps in the process are the same no matter which type of desalination technology is used. This is simply because the mechanism for transporting water to and from the desalination unit is independent of the technology used.

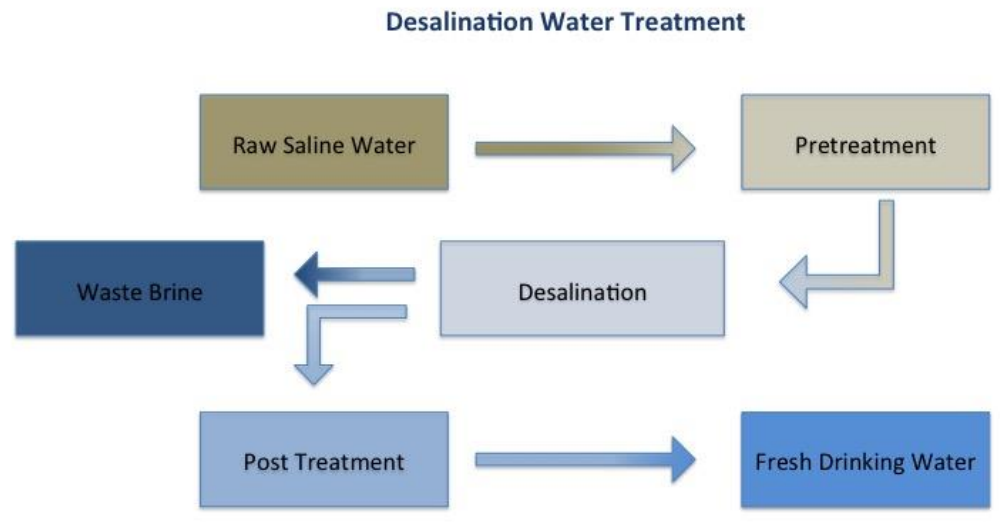

Figure 11: Flow diagram of the steps involved in desalination water treatment The main steps include 1) pre-treatment, 2) desalination and 3) post-treatment. Source: Clayton (2011)

\section{Although pre-treatment and post-treatment may differ between} technologies, raw water quality is the biggest determiner of pre-treatment needs. The post-treatment needs are determined based on both the choice of desalination technology and the purpose of treated water (drinking, irrigation, cleaning).

\subsubsection{Pre-treatment}

The pre-treatment for thermal technologies like SSD is very simple, requiring at most a filtration step before desalination. This is because these technologies work via evaporation and condensation and so there is no need to worry about contaminants clogging the device or membranes. In contrast, technologies that use membranes, which are highly prone to fouling, are dependent on pre-treatment to work properly and for sustained periods of time. The amount of pre-treatment necessary depends on the raw water quality. Table 4 provides a breakdown of different types of fouling, their causes and the types of pre-treatment required.

Of the membrane-containing technologies (EDR, mCDI and RO), RO often requires the most extensive pre-treatment. 
Table 4: Membrane foulants and corresponding pre-treatment steps

\begin{tabular}{|l|l|l|}
\hline Type of fouling & Foulant & Appropriate pre-treatment \\
\hline Biological & $\begin{array}{l}\text { Bacteria, micro-organisms, } \\
\text { viruses, protozoa }\end{array}$ & Chlorination \\
\hline Particle & $\begin{array}{l}\text { Sand, clay } \\
\text { Organic and inorganic } \\
\text { complexes, micro-algae }\end{array}$ & Filtration \\
\hline Organic & $\begin{array}{l}\text { Natural organic matter (NOM), } \\
\text { humic and fulvic acids, } \\
\text { biopolymers }\end{array}$ & $\begin{array}{l}\text { Coagulation + filtration } \\
\text { carbon adsoprtion + ultra-filtration }\end{array}$ \\
\hline Mineral & $\begin{array}{l}\text { Calcium, carbonates, } \\
\text { magnesium barium or strontium } \\
\text { sulphates }\end{array}$ & Anti-scaling dosing, acidification \\
\hline Oxidant & \begin{tabular}{l} 
Chlorine, ozone \\
\hline
\end{tabular} & $\begin{array}{l}\text { Sodium bisulphite, metabisulphite, } \\
\text { activated carbon }\end{array}$ \\
\hline
\end{tabular}

Source: adapted from LennTech (1998)

Assuming highly contaminated source waters, an example of necessary pre-treatment steps for RO is as follows: 44

Step 1. Removing biological foulants: An extremely effective, and technically and economically feasible, way to remove biological contaminants is with chlorination. This is often done in step 1 but, unfortunately, since RO membranes are highly sensitive to chlorine, the water must be dechlorinated before desalination (Step 5).

Steps 2-4. Removing organic, colloidal and mineral foulants: Depending on concentrations of raw water contamination, this is often done through coagulation (step 2), flocculation (step 3) and sedimentation (step 4).

Step 5. Removing added chlorine: There are a variety of ways to remove chlorine. Common approaches include dosing with sodium bisulphite or metabisulphite or using an activated carbon filter. Both of these methods are reasonably inexpensive.

Step 6. Mitigating scaling: An anti-scalant solution is added to the water to mitigate the build-up of calcium carbonate and sulphates on the membranes.

Step 7. Removing whatever is left: The final pre-treatment step is fine filtration ( 5 micron filter), which prevents any small lingering debris or other materials from clogging the system and damaging the membranes.

EDR and mCDI vs. RO: The advantages of EDR and $\mathrm{mCDI}$ over $\mathrm{RO}$ are that the ion-exchange membranes used in charge-based technologies have much higher resistance to chlorine, are not as easily affected by exposure to $\mathrm{pH}$ values of $0-10$ and are less prone to fouling than thin film polyamide membranes. ${ }^{45}$ Thus pre-treatment, although still important, is not as critical or as extensive as for RO. 


\subsubsection{Post-treatment}

Desalinated product water must meet all local water standards before it is distributed to the community. Common treatments that may be required post-desalination to ensure this include $\mathrm{pH}$ adjustment, remineralization and disinfection.

\section{pH adjustment}

$\mathrm{RO}$, EDR and $\mathrm{mCDI}$ permeate can be slightly acidic, so sodium hydroxide or sodium bicarbonate may need to be added to raise the $\mathrm{pH}$ level to the suggested drinking water $\mathrm{pH}$ range of 6-8.

\section{Remineralization}

Desalinated water from SSD and RO is mostly deionized and, as mentioned earlier, some salinity is essential for both the health and taste of drinking water. Thus, water treated by both SSD and $\mathrm{RO}$ requires remineralization prior to consumption (the healthy range is between 300 and 600 $\mathrm{ppm}$ ). This is not necessary for EDR or $\mathrm{mCDI}$, which by design do not completely deionize the water and can produce water with salinity in the healthy range. It is worth noting here that, although WHO's salinity guidelines range from 300 to 600 ppm, consumers may prefer the taste of lower-salinity water. It really comes down to what the specific consumer is accustomed to.

\section{Disinfection}

This is likely to be necessary for all desalination technologies to remove any water-borne pathogens. This is especially the case if water is being stored for prolonged periods of time, especially in warm climates. Common disinfection practices include chlorination and ultraviolet (UV) treatment. 


\section{ENERGY NEEDS AND COST OF DESALINATION TECHNOLOGIES 2.1 ENERGY}

\subsubsection{Energy requirements}

\section{One of the main drawbacks of desalination technologies is that they often require 3-4 times more energy than conventional water treatment. ${ }^{46}$}

Typically, the amount of energy needed to treat surface waters so that they are of drinking quality requires $0.36 \mathrm{kWh} / \mathrm{m}^{3}$, while seawater desalination can require 3.6 to $4.6 \mathrm{kWh} / \mathrm{m}^{3}$, an increase of $10-13$ times ${ }^{47}$ Desalination of brackish water requires less energy, somewhere between 0.3 and $2.5 \mathrm{kWh} / \mathrm{m}^{3}$, but it is still energy-intensive in comparison with other water treatment processes, as shown in Figure $12 .{ }^{48}$

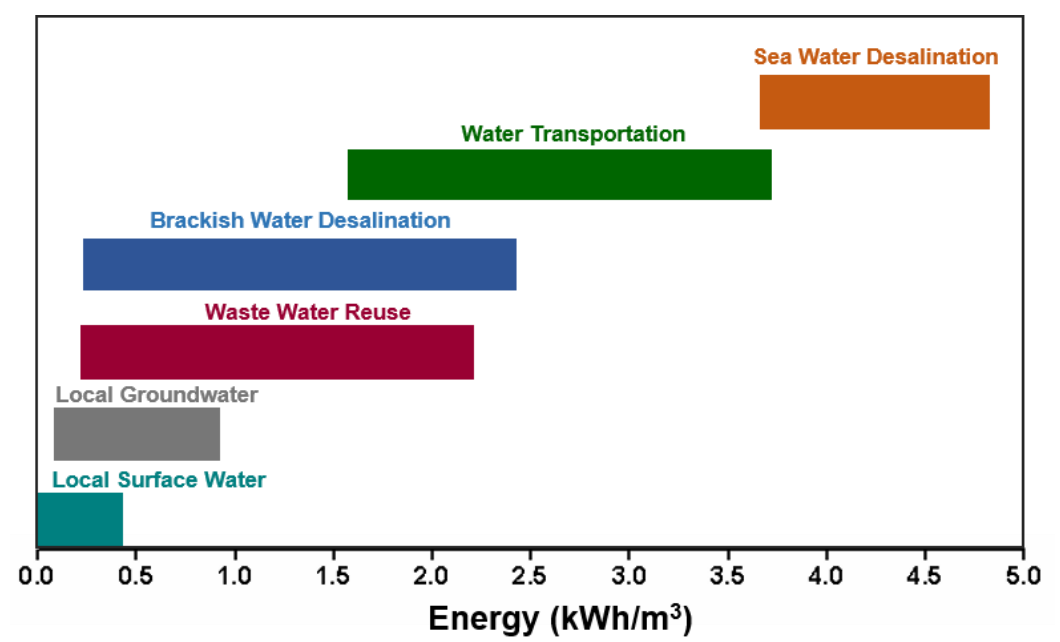

Figure 12: Energy required to produce drinking water from various sources of water in California Methods include desalinating water from the Pacific Ocean and treating and transporting fresh water from the Colorado River.

Source: adapted from Cooley and Gleick et al (2006)

Beyond the water treatment step, calculating the energy needed to supply fresh water must also include necessary actions like water intake, pre- and post-treatment and brine discharge. In general, one should assume at least $1 \mathrm{kWh} / \mathrm{m}^{3}$ in addition to the energy required for desalination to account for these functions. That said, within the water treatment process as a whole, the 
desalination step is considerably more energy-intensive than all other steps, so the following sections focus on energy requirements for the desalination step alone.

An ideal desalination technology in terms of energy will operate at or very close to the theoretical minimum energy required to separate salt from water. This theoretical minimum can be calculated using thermodynamics, and is a function of the salinity of the source. It is important to note that the theoretical minimum energy is independent of the technology being used (thermal, charge-based or membrane).

\section{The theoretical minimum energy for desalination of seawater $(35,000 \mathrm{ppm})$} with a $50 \%$ water recovery rate is calculated to be $1.06 \mathrm{kWh} / \mathrm{m}^{3}$, regardless of whether RO, ED, mCDI or MSF is the technology used for desalination. ${ }^{49}$

This value is the bare minimum energy required for the desalination of seawater, and no technology can go below it, no matter how advanced.

\section{In practice, no technology has met the thermodynamic threshold, but with} all the R\&D invested in it over the years, $R O$ is getting close.

Figure 13 shows the decrease in energy required per $\mathrm{m}^{3}$ of seawater desalinated using $\mathrm{RO}$ technology as a function of time. In 1970 , energy requirements were as high as $16 \mathrm{kWh} / \mathrm{m}^{3}$ but in the last decade they have dropped significantly, to around $1.75 \mathrm{kWh} / \mathrm{m}^{3}$. This considerable improvement in the efficiency of RO technology makes it stand out from the other desalination options, which are in much earlier stages of development. It should also be noted, however, that the low energy numbers for $\mathrm{RO}$ facilities are often reported from large plants processing hundreds of millions of litres per day, which use a massive scale of production to minimize energy use. These facilities also tend to utilize energy recovery devices that significantly add to capital costs..$^{50}$ In general, source salinity and production rate are the main factors that influence energy consumption. The following sections use these factors to compare the major desalination technologies.

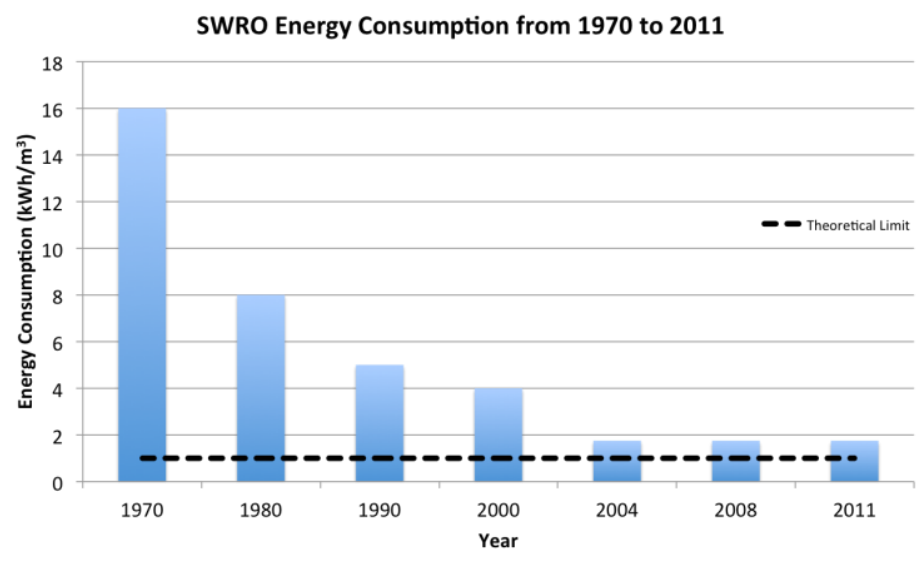

Figure 13: Increased energy efficiency of RO technology The figure shows the decrease in energy consumption of seawater RO plants from 1970 (when they used on average around $16 \mathrm{kWh} / \mathrm{m}^{3}$ ) to 2011 (around $2 \mathrm{kWh} / \mathrm{m}^{3}$ ). The dashed line is the theoretical minimum. Source: adapted from Elimelech (2011) 
The theoretical energy consumption for membrane and charge-based separation processes is shown in Figure 14. Thermal desalination technologies (MSF, MED, VCD and SSD) are not shown because they are all extremely energy-intensive, with energy requirements ranging from 10 to $27 \mathrm{kWh} / \mathrm{m}^{3}{ }^{51}$ Due to their high energy demands, thermal technologies are limited to seawater desalination and are not considered for treatment of lower-salinity sources such as brackish water. In fact, even for seawater sources, thermal facilities often only become economically viable when operated in conjunction with thermal power plants. This way, the waste heat of the power plant supplies the energy needs for thermal desalination at little to no additional cost. However, this energy-saving technique requires the existence of a large, functioning power plant and is not realistic for communities interested in small to mid-size desalination facilities.

The more technologically advanced thermal options - MSF, MED and VCD - are not practical in terms of energy use for small communities in South and Southeast Asia.

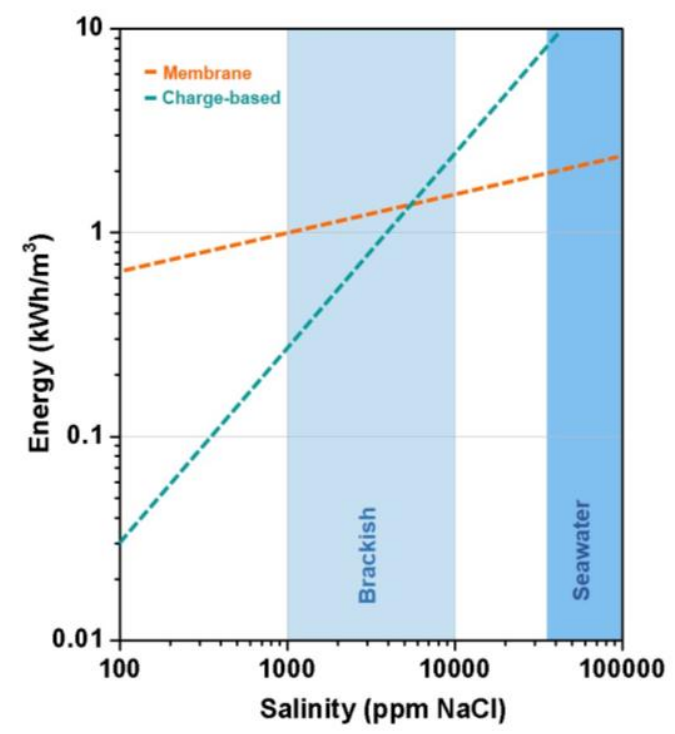

Figure 14: Theoretical energy consumption as a function of source water salinity for membrane and charge-based technologies

Thermal technologies are not represented here as they require significantly more energy (23$27 \mathrm{kWh} / \mathrm{m}^{3}$ ) and are much less dependent on source salinity.

Source: adapted from Oren (2008) and Wright and Winter (2014)

Eliminating thermal technologies from the discussion, we can focus now on a comparison of membrane and charge-based processes.

Theoretically, charge-based processes are more favourable in terms of energy use than membrane separation for raw waters with a salinity of less than $5,000 \mathrm{ppm}$ (Figure 14). However, in practice this salinity max will be considerably lower. Most of the successfully demonstrated mCDI and EDR technologies have not treated waters above $3,500 \mathrm{ppm}$. 
Above a value of $3,500 \mathrm{ppm}$, membrane processes are still preferred. There is potential in the future for charge-based technologies to be energy efficient up to $5,000 \mathrm{ppm}$, as compared to membrane technologies, but there is little demonstrated proof that this is the case in 2018.

Field reports confirm that ED uses 35\% less energy than RO for low-salinity brackish water at $2,633 \mathrm{ppm}$, while RO uses $27 \%$ less energy than ED for higher-salinity brackish water at 5,292 ppm (Table 5)..$^{22}$ The explanation for this can be thought of simply as follows: RO functions by separating water from salt and thus its energy needs are less dependent on source salinity, so energy consumption remains relatively constant even as salinity increases. Charge-based technologies, however, separate salt from water and thus their energy needs are highly dependent on source salinity and they require extensive amounts of energy $\left(>5 \mathrm{kWh} / \mathrm{m}^{3}\right)$ for higher-salinity sources ( $>3,500 \mathrm{ppm})$.

Source salinity can be a key deciding factor in choosing between RO and mCDI or EDR technologies for the treatment of brackish water.

Table 5: Energy requirements for brackish water desalination using RO and ED in Tunisia

\begin{tabular}{|l|r|r|r|}
\hline Water source & Salinity $(\mathbf{p p m})$ & $\mathbf{R O}\left(\mathbf{k W h} / \mathbf{m}^{\mathbf{3}}\right)$ & $\mathbf{E D}\left(\mathbf{k W h} / \mathbf{m}^{\mathbf{3}}\right)$ \\
\hline Source A & 2,633 & 0.81 & 0.53 \\
\hline Source B & 5,292 & 1.09 & 1.50 \\
\hline
\end{tabular}

Source: adapted from Walha and Amar et al (2007)

\subsubsection{Energy sources}

Desalination technologies can be powered by either thermal or electrical energy. Sources of thermal energy include solar power and fossil fuels (natural gas, coal, oil), and sources of electrical energy include fossil fuels and renewables (solar, wind and wave power). This section discusses different sources to power desalination technologies.

\section{Fossil energy sources}

Most desalination facilities today are powered by fossil fuels, either by the electricity grid or by a diesel generator. The advantage of fossil fuels is that they are reliable, making production consistent and dependable. Their main disadvantage is their chemical by-products, which are harmful to the environment and to human health, both immediately and in the long term. Tapping into the grid is an obvious choice if electricity is cheap and dependable. If the community is offgrid, then the choice is between a diesel generator and various renewable energy sources.

\section{A financial decision to fully operate a desalination plant using diesel} depends to a great extent on the local cost of materials and fuels. Two studies done in 2011 confirmed that, for desalination facilities located in remote areas requiring less than $3 \mathrm{kWh} / \mathrm{m}^{3}$, with capacities of less than $70 \mathrm{~m}^{3} /$ day and with adequate solar radiation, the operating expenses of solar power made it more economically advantageous than diesel (for further discussion, see section 2.2). ${ }^{53}$ 
That said, the choice of using a diesel generator might still be preferred to solar panels. Considering that diesel generators have been around for a long time and are widely used in rural areas, it is likely to be easier to find individuals with the ability to operate and maintain them than it would be for solar panels. This means that the facility is more likely to stay in operation for longer. Diesel generators do, however, potentially pose health hazards to the community at large if the plant is in a densely-populated area and/or there are vulnerable populations close by.

\section{Renewable energy sources}

The use of renewables is highly attractive because it gives off-grid communities pollution-free access to desalination technologies and reduces the global carbon footprint. The main disadvantage of renewables is that they are intermittent - i.e. the sun does not always shine and the wind does not always blow. For this reason, some sort of energy storage system is often necessary, which is discussed in detail below.

The following sections evaluate the appropriateness of different renewable sources (solar, wind and wave power) for various technologies in South Asia and discuss appropriate storage and back-up power options. As this discussion progresses, it should be kept in mind that understanding the technical and operational capacity of the local community is critical in determining whether renewable options are appropriate.

\section{Solar energy}

As already mentioned, the main thermal technologies (MSF, MED and VCD) require extensive energy use. One way to make thermal technologies feasible for small-scale use is by utilizing solar energy directly, which operationally is free. The most commonly installed direct solarthermal systems are SSD. SSD facilities involve no recurring energy costs, but they require high capital investment, have low throughputs $\left(2-5 \mathrm{~L} / \mathrm{m}^{2} /\right.$ day) and require extensive amounts of land. ${ }^{54}$ These aspects of SSD often mean that the costs are greater than the benefits.

Solar energy can also be used indirectly by connecting photovoltaic (PV) panels to a $D C \rightarrow A C$ converter to power RO, EDR and $\mathrm{mCDI}$ installations. It is likely that this is a feasible option for regions in northern Africa and South Asia, where the sun is a powerful and abundant energy source. In India, more than two-thirds of the country receives more than $4.5 \mathrm{kWh} / \mathrm{m}^{2} /$ day of solar radiation; assuming solar panels with an energy conversion efficiency of $20 \%$, this means that one square metre of PV panels can supply about $1 \mathrm{kWh} / \mathrm{day} .{ }^{55}$

\section{Assuming that the energy needs of a desalination facility are $2-5 \mathrm{~kW} / \mathrm{h} / \mathrm{m}^{3}$, $20-50 \mathrm{~m}^{2}\left(215-538 \mathrm{ft}^{2}\right)$ of solar panels are necessary to operate a plant producing $10 \mathrm{~m}^{3} /$ day. $^{56}$}

An issue to consider with solar power is that it adds to the initial cost of a desalination plant, due to the need to purchase PV panels, a control system, inverters and batteries. In India, companies such as Tata have delayed investing in solar-powered $\mathrm{RO}$ because, as of 2017, the capital investment required for such a facility was roughly $58 \%$ higher than for diesel- and grid-powered RO. ${ }^{57}$ However, with time and further investment these costs are likely to fall. It is also worth noting that an advantage of PVs is that once they are installed they do not require significant expenditure to maintain, and energy costs can be significantly lower than for grid-powered facilities. If initial investment in the plant is not a major concern, then solar power is likely to be an economically and environmentally suitable option. 


\section{Wind energy}

The potential for off-grid wind-powered desalination facilities depends on there being sufficient wind velocity and frequency.

\section{A study done in 2007 found that wind energy can be used effectively for small-scale facilities as long as the average velocity is more than $5 \mathrm{~m} / \mathrm{s}_{.}{ }^{58}$}

It is possible for regions in South and Southeast Asia to meet this requirement but, in order to ensure that it is realistic for specific locations, wind modelling and data collection should be carried out. As an example, researchers from Queen's University in Canada modelled wind patterns in the Mekong Delta in Vietnam to evaluate which regions would be suitable for desalination powered by wind turbines. ${ }^{59}$ In general they found that wind was a viable option for the Mekong Delta.

Note that technical capacity may be needed within the community to maintain and operate windpowered facilities. Wind turbines have developed significantly over the past decade, but they still require maintenance that may go beyond the skills of local operators. They also require a lot of space, and work will need to be done to make sure that turbines will be accepted under local land regulations. Additionally, the cultural and aesthetic acceptance of large wind turbines may vary from community to community. In recent years, dozens of small to mid-size wind turbines have been installed in Indian towns (e.g. Chitradurga in Karnataka) for power generation. ${ }^{60}$ In general, wind is a renewable source of energy that is gaining in popularity and is worthwhile considering, with the above caveats in mind.

\section{Wave energy}

There is a mixture of both direct and indirect wave-powered desalination technology in development. All the current pilot plants using either direct or indirect wave energy are coupled with $\mathrm{RO}$ units. Wave-powered desalination on a commercial scale is relatively new; the first facility became operational in 2015 on Garden Island in Western Australia, with a capacity of $150 \mathrm{~m}^{3} /$ day. ${ }^{61}$ This system powers an RO plant indirectly, meaning that wave energy is first converted into electrical energy, which is then used to power the RO facility. Though foundational and exciting, this kind of technology requires significant pre-established development, such as a dynamic grid system capable of adapting to a new energy source. It is unlikely that such a facility would be a feasible option for small communities in South and Southeast Asia.

\subsubsection{Robustness of different technologies}

Evaluating the robustness of a technology to intermittent power supply is only relevant for facilities powered by electricity. For SSD, robustness is not an issue because either the sun shines or it does not; it has no impact on the equipment or the lifetime of the technology. The case is theoretically similar for direct wave-powered RO. There is a slight chance, though, that the lifetime of the materials for either system may be less predictable if operation is highly inconsistent, and this is something worth considering.

All desalination technologies that are powered by electricity - RO, EDR and $\mathrm{mCDI}$ - can tolerate intermittent operation as long as they are designed and maintained properly. ${ }^{62}$ For $\mathrm{RO}$, there are two main issues that need to be considered - back flow and stagnation. Back flow can happen if 
there is an unexpected power loss and the high-pressure pumps turn off. If this occurs, the water, which was originally being forced through the system in the expected direction for RO may flow backwards (depending on the pressure differential) and can irreversibly damage the membrane, in addition to resalinizing the fresh water already produced. As long as there are check valves in place this will not happen, so it is important to make sure that such safety features are included in the design. The second issue is stagnation of water, which will increase fouling on the membranes. This is manageable as long as the proper cleaning maintenance is done. In general, the manufacturer should have already considered both issues when designing the unit, and the job of the entity establishing the treatment facility should simply be to confirm that the safety measures are included.

For charge-based technologies like ED and $\mathrm{mCDI}$, back flow is not an issue, but increased fouling due to stagnation can be. Proper cleaning and maintenance can help take care of this.

\subsubsection{Energy storage and energy back-up needs}

Dealing with intermittent energy sources requires either energy storage or energy back-up. Conventional energy storage would mean a battery, which stores extra energy when the source is supplying power but the plant is not operating. An alternative option is to build an oversized facility so that extra water can be produced and stored in a reservoir for consumption when there is no power. ${ }^{63}$ Both options will require higher initial capital investment and also maintenance, which should be evaluated with the specific location and community in mind. The larger plant will naturally require more land, which could be a drawback for communities living in areas with a high population density. Further, when it comes to the storage of treated water in tropical weather, the high chance of contamination from biological agents is a concern, and the storage system must be adequately designed to reduce contamination by pathogens. Although there are various new types of battery, the only options that are currently cost-effective are lead-acid batteries. ${ }^{64}$ Used batteries must be appropriately recycled; the improper disposal of lead-acid batteries has significant environmental impacts and can contaminate local water supplies. Unfortunately, more often than not there is no recycling or safe battery disposal process in place for small communities in South and Southeast Asia.

A common back-up energy supply is a diesel generator. Coupling a renewable system like solar or wind with a diesel generator is often referred to as a hybrid system. In general, as has already been discussed, the advantages of diesel generators include reliability and easy accessibility, while disadvantages include air and noise pollution.

\section{Energy requirements for desalination: summary}

The thermodynamics of saltwater separation dictate the minimum energy needs of desalination; however, practically all desalination technologies require between two and 20 times that minimum threshold. Thermal desalination technologies like MSF, MED and VCD are energy-intensive and are usually optimized to operate in conjunction with thermal power plants for seawater desalination; thus, they are not ideal for brackish water desalination in small communities. 
Solar stills source all their energy from the sun and are hence a viable thermal desalination option, but they are best suited for use at household scale due to their low water outputs.

The most practical option for seawater desalination in coastal communities in terms of energy is $\mathrm{RO}$, with energy consumption as low as around $1.75 \mathrm{kWh} / \mathrm{m}^{3}$ at $50 \%$ water recovery rate. However, for treating low-salinity inland brackish water (<3,500 ppm) charge-based technologies such as EDR and $\mathrm{mCDI}$ are much more energy-efficient, typically using $<1 \mathrm{kWh} / \mathrm{m}^{3}$ and have higher water recovery rates (85-90\%).

All desalination technologies can be powered by renewable energy sources. Although this report gives examples of solar, wave and wind power, other renewable sources such as geothermal are also a possibility. The decision to use or not use renewables depends on the availability of certain renewable sources based on location, ability of the community to pay for renewable energy generation systems and associated energy storage or back-up options, and on the technical capacity of local engineers and operators.

\subsection{COST}

Deciding which technology and what energy source are appropriate for a particular community often comes down to economic feasibility. This report defines a desalination technology to be economically feasible if the operation, maintenance and final cost of the water produced is within the community's financial means. This section determines and compares the total cost of different technologies as a combination of two types of expense:

- capital expenditure (CAPEX): one-time costs that occur in the construction and installation phase of the plant;

- operational expenditure (OPEX): continuously recurring expenditures to keep the plant functioning.

The way of reporting OPEX is usually standardized as per $\mathrm{m}^{3}$ of water treated; for convenience of comparison, this report lists all expenses in US dollars.

\subsubsection{CAPEX}

The breakdown of capital costs for all technologies includes the cost of the equipment, installation, land and any necessary buildings to house the plant. For reference, a report done on desalination units in the USA found the top three expenses for RO plants to be equipment and materials $(25.4 \%)$, civil engineering costs (15.8\%), and piping (12.3\%). ${ }^{65}$ 
Table 6 shows that a reasonable price to be paying for a small-scale, $1-10 \mathrm{~m}^{3} /$ day desalination unit is around $\$ 5,000$, and it is possible to get both a grid-powered $\mathrm{RO}$ and grid-powered $\mathrm{mCDI}$ unit for this price. Grid-powered RO units are much more widely available and are sold in a range of capacities and prices (from less than $\$ 5,000$ based on membrane quality), while grid-powered $\mathrm{mCDI}$ units are not as widely available and are likely to be more expensive (up to $\$ 8,000$ ), due to low volumes of sales. If considering renewable energy sources, it is worth noting that the cost of solar-powered $\mathrm{RO}$ is roughly two to 20 times greater than that of grid-powered $\mathrm{RO}$, making it financially unattractive. ${ }^{66}$ There is still hope that solar-powered desalination will become more economical, with promising early results from MIT and Tata Projects on solar-powered EDR (see section 3) ${ }^{67}$ However, as of 2017, solar-powered EDR is still in the early stages of development and requires optimization and scale-up prior to commercialization.

\section{Table 6: Unit cost for commercially available desalination technologies}

The costs shown are for facilities with a capacity of 1-10 $\mathrm{m}^{3} /$ day, except for SSD, which produces only 16-18L/day. Information based on multiple direct quotes from commercial companies.

\begin{tabular}{|l|l|r|r|r|}
\hline Technology & $\begin{array}{l}\text { Grid- } \\
\text { powered RO }\end{array}$ & $\begin{array}{l}\text { Solar- } \\
\text { powered RO }\end{array}$ & $\begin{array}{l}\text { Grid-powered } \\
\text { mCDI }\end{array}$ & \multicolumn{2}{|l|}{ SSD } \\
\hline $\begin{array}{l}\text { Unit cost } \\
\text { (US\$) }\end{array}$ & $4,000-8,000$ & $20,000-$ & $5,000-11,000$ & $\begin{array}{r}450(45,000 \text { for } \\
\text { production of } \\
\left.1.6 \mathrm{~m}^{3} / \text { day }\right)\end{array}$ \\
\hline
\end{tabular}

\subsubsection{OPEX}

\section{For most technologies, energy is the primary operating cost, accounting for as much as $50-75 \%$ of the total. ${ }^{68}$}

Besides energy, operating costs include chemical cleaners, replacement parts (membranes, electrodes, pumps), brine disposal, labour and management, and maintenance, both electrical and mechanical. These factors make OPEX highly variable, depending on the region the treatment facility is located in. With this in mind, the following sections discuss and compare different technologies in the context of specific factors contributing to OPEX.

\section{Energy}

With energy consumption being such a significant part of the desalination process, it is not surprising that it dominates OPEX. As an example, the electricity costs of a village-scale gridpowered RO system for treating brackish water in India account for $54 \%$ of OPEX. Using the same system for seawater desalination bumps the electricity usage up even further, accounting for $63 \%$ of OPEX. ${ }^{69}$ With such high recurrent expenditures, it is justifiable to consider lowerenergy alternatives to grid-powered $\mathrm{RO}$, such as powering the system with $\mathrm{PVs}$ or using technologies like EDR and $\mathrm{mCDI}$, which have lower energy consumption for brackish water desalination (TDS $<3,500 \mathrm{ppm}$ ). 


\section{Chemical inputs}

Chemical addition is often a necessary part of pre- and post-treatment in order to increase the longevity of the desalination unit and reliably deliver high-quality drinking water. As with conventional water treatment methods, steps such as coagulation, flocculation, filtration and chlorination are carried out to avoid scaling and biofouling. For $\mathrm{RO}$, a dechlorination step is necessary after pre-treatment because chlorine causes irreversible damage to $\mathrm{RO}$ membranes. Membranes in $\mathrm{mCDI}$ and ED/EDR are much more resistant to chlorine, and this could reduce the cost of chemical inputs for pre-treatment. ${ }^{70}$

For seawater RO, chemical costs can account for as much as $9 \%$ of OPEX because the water that goes into the desalination unit must be free of contaminants to prevent membrane fouling. ${ }^{71}$ The same is true for brackish water $\mathrm{RO}$, but usually there are fewer contaminants in brackish groundwater, and thus less chemical pre-treatment is needed. Similarly, fewer chemicals are needed for EDR, mCDI and SSD for brackish water treatment, due both to lower influent water salinity and the basic operating principles of the technologies. In $\mathrm{RO}$, water is pushed through a membrane using high pressure, leading to packing of contaminants on the membrane surface and causing fouling. In charge-based separation methods, the issues of fouling are far less of an issue, since the membranes act as an ion-selective barrier instead of a filtration membrane.

Besides pre- and post-treatment, for $\mathrm{RO}$, chemicals are needed to clean the membranes themselves. Cleaning is recommended when the influent flow drops $10 \%$ below normal; for example, if a typical operation is $800 \mathrm{LPH}$ and it drops to $720 \mathrm{LPH}$, membrane cleaning should be performed. Typical cleaning chemicals include hydrochloric acid for the removal of scale and sodium hydroxide for the removal of biofilms and organics. ${ }^{72}$ The cleaning costs will correspond to the frequency of cleaning, which depends on daily production and the quality of feed water.

Overall, chemical costs are highly dependent on raw water quality and the sensitivity to fouling of the specific technology. Membrane cleaning, which is necessary for RO, $\mathrm{mCDI}$ and EDR technologies, must follow the exact procedure recommended by the manufacturer, taking into consideration the local raw water quality as well as other specifications of the installation.

\section{Replacement parts}

Membrane replacement is a significant and consistent maintenance cost. This is not an issue for thermal technologies like SSD, but it is relevant for RO, EDR and $\mathrm{mCDI}$. Even though membranes serve different functions in RO than they do in ED/EDR and $\mathrm{mCDI}$ (one for water permeation, the other for ion selectivity), fouling is a significant issue for both. Based on conversations with companies supplying desalination technologies, RO membranes tend to last between one and three years and $\mathrm{mCDI}$ and EDR membranes approximately five years for similar feed water quality and use. Here we would like to note that the lifetime estimates for $\mathrm{mCDI}$ and EDR are based on limited field data.

All the technologies discussed here are designed to be modular, where a single cell stack or a membrane cartridge can be replaced during maintenance. The modular design allows for quick detection of failure points, which can then be easily addressed without too much disruption to the overall process. Most commercial desalination companies that use membranes make this a priority in their design, and it may be worthwhile for local operators/technicians to evaluate the ease of working with a given modular design. 
It is challenging to put exact prices on membranes and compare them across technologies, because cost will vary depending on the manufacturer and quality of the membrane. Also, membrane cost is usually built into the initial capital expense of the unit, and the number of membranes is different depending on capacity, making it challenging to generalize about replacement costs.

\section{Since RO is the leading desalination technology, it tends to have cheaper costs for membranes, largely due to optimized manufacturing.}

There are companies that sell membranes for small-scale (around $0.5-4.5 \mathrm{~m}^{3} /$ day) units for $\$ 100$ 200 each. Units of this size need only 1-2 membranes, which have typical lifetimes of 1-2 years (of course this is highly dependent on use and influent water quality). By contrast, as an example, membranes for a $1 \mathrm{~m}^{3} /$ day EDR unit treating water with an initial salinity of $3,000 \mathrm{ppm}$ last approximately five years and cost $\$ 1,500$ to replace. ${ }^{73}$

Besides membranes, other major replacement parts include pumps, which are required for all technologies, and electrodes for charge-based technologies. In certain cases, such as mCDI, the membrane and electrode form a single unit and are replaced together. Obviously, these costs vary greatly depending on local availability of replacements, and must be considered when evaluating different technologies. It is worth noting, however, that RO (unlike other technologies) requires high-pressure pumps in addition to the regular pumps used to move water through the system.

\section{The maintenance and operation of these special high-pressure pumps is crucial to the operation of RO and may be a challenge for small communities.}

\section{Brine disposal}

There are a variety of brine disposal methods, including brine lines, surface water discharge, disposal to sewer, sub-surface injection, evaporation ponds, landfills, land applications and zero liquid discharge (ZLD). ${ }^{74}$ Each is described briefly below and then discussed in terms of their application to different technologies and cost.

\section{Brine line}

Refers to a pipeline that uses gravity (or pumping in rare cases) to transport brine to coastal wastewater treatment plants. The large volume of wastewater dilutes the salinity of the brine and after treatment the mixture is disposed of in the ocean. This option is usually only used for inland treatment plants that have considerable resources to invest in the necessary infrastructure to build and maintain a brine line. Unfortunately brine lines are often resource-intensive and too expensive for small communities, unless there is outside support. ${ }^{75}$ Southern California has two brine lines in operation but the economic feasibility of building and operating a third system has been under discussion for over 40 years, with little progress. The large amounts of capital required to build the pipeline mean that this option must be government-funded and so it is a less likely choice for small, remote and rural communities in South and Southeast Asia. 


\section{Surface water discharge}

Refers to disposing of desalination effluent into surface waters, which include rivers, streams, estuaries, lakes, canals or coastal waters. ${ }^{76}$ This is typically a low-cost solution, but it is important that local regulations are followed appropriately. Permits for disposal can add cost, and also surface water discharge is likely to be phased out in future as a way to minimize salinization of freshwater sources.

\section{Disposal to sewer}

Refers to disposing of effluent into nearby sewers; it may or may not be treated later by a wastewater treatment facility, depending on local infrastructure and the technical capacity of the community.

\section{Evaporation ponds}

Refers to large but shallow artificial ponds used to evaporate out water and leave behind salts. If groundwater regulations are stringent in the area concerned, then these ponds can be expensive to build and maintain according to local codes. ${ }^{77}$ The cost of land is an important factor in determining if evaporation ponds are a reasonable option. Further, the choice of using an evaporation pond must consider the salinity of the brine. Generally, brine from brackish water desalination tends to be of lower salinity and therefore difficult to evaporate to solid salt. Brines from seawater desalination on the other hand tend to be much more saline, but are easier to dispose back into the sea, so evaporation ponds are not preferred.

\section{Landfills}

Refers to dumping brine straight into landfills. Similar to sewer disposal, this is only economically viable if the dump site is in the vicinity of the treatment plant. Otherwise a large piped disposal system must be built, which can be quite costly.

\section{Land applications}

Refers to spraying brine on the land, often specifically for agricultural irrigation. If this method is chosen, it is important to make sure that the crops and soil can manage the brine sustainably.

\section{Sub-surface injection}

Refers to the injection of brine into already saline groundwater or porous rocks. With this method, care needs to be taken to ensure that the brine disposed of does not contaminate the source water. This option can also be expensive and requires high technical skill, because an injection well must be dug and maintained. For these reasons, injection is not likely to be a viable option for small rural communities.

\section{Zero liquid discharge}

Refers to practices that avoid liquid waste products by converting most feed water into fresh water and producing just a solid salt waste. Generally, the concentrated brine is processed using advanced evaporation techniques to recover most of the water, leaving behind only solid precipitates. ${ }^{78}$ Unfortunately, this method is both energy- and cost-intensive; a facility capable of treating $228-684 \mathrm{~m} 3 / \mathrm{hr}$ costs between $\$ 25 \mathrm{~m}$ and $\$ 50 \mathrm{~m} .{ }^{79}$ This method is only really used for 
large-scale industrial processes requiring water recovery and is not practical for small-scale desalination facilities in South and Southeast Asia.

Often, the choice of brine disposal method is determined by the geographical location of the desalination facility. For example, coastal facilities can discharge their brine to the ocean while those further away from the coast may need to consider evaporation ponds or transportation to the coast. Beyond coastal proximity, factors such as land value and land availability affect the choice of brine disposal method. In general, inland desalination operations have fewer options and face higher costs for brine disposal compared with coastal installations.

Finding economic value in waste brine is the ideal solution - i.e. getting paid for the brine instead of paying to dispose of it. While researchers have extensively explored ways to revalorize waste brine, promising solutions remain elusive, however. Repurposing brine has been limited for two main reasons: 1) brine contains a mixture of different salts and its composition can be highly variable depending on the source water; and 2) separating the different salts contained in the brine is energy-intensive, and the separated salt products are not of high economic value. While separating the salts from a brine stream is not economically attractive, using the salt mixture for industrial applications that are not sensitive to salt composition is a possible option. However, this requires the desalination plant to be co-located with relevant industries that use salt, such as glass manufacturing, to avoid the cost and burden of brine transport.

Technically, brine management methods are independent of which desalination technology is used, meaning that any technology can deploy the above methods.

\section{Different technologies, however, will produce more or less brine depending on their efficiency in water recovery. Additionally, the source water determines the brine salinity. Brine disposal costs are directly related to both the amount of brine produced and salinity of the brine. Since source water choice is generally non-negotiable, one approach to minimizing brine disposal costs is to select a technology that has a very high water recovery rate and subsequently low brine production for given source water.}

Waste volumes from brackish water desalination using $\mathrm{RO}$ are in the range of $20-80 \%$, compared with 10-15\% from ED and mCDI. This difference is significant for brackish water facilities located inland, which often either have to transport the waste to the sea or purchase large land areas for evaporation ponds.

\section{Labour, management and maintenance}

These costs are very challenging to generalize about, since they are highly dependent on the region of interest. Solar stills are arguably the most user-friendly and easy system to manage, while RO is the most technically advanced, using high-pressure pumps. Due to this the price for labour, management and maintenance will be higher for RO than for SSD, while EDR and mCDI fall in between these two on the general spectrum.

One way to reduce labour, management and maintenance costs is to make operation of the plant fully automatic. This removes the need for a trained operator, and ideally reduces routine maintenance. This will, of course, increase capital costs, but it has the potential to increase longterm use of the facility. The appendix lists potential technology unit manufacturers and suppliers that offer fully automated facilities. Interestingly, however, a case study done by MIT researchers 
found that villagers in India preferred a manual system to an automatic one because 1) it was what they expected, fitting into their cultural norms; 2) they wanted someone at the plant to manage water sales and distribution; 3 ) it offered employment; 4) they were concerned that an automated facility would have higher rates of failure, and that they would not be able to fix it if it broke down; and 5) they did not want to pay the extra initial installation costs. ${ }^{80}$ Thus the MIT group decided to make its next unit manual in order to increase user adoption and acceptance. For the future, they believe that, for small desalination facilities, a hybrid system with both automatic and manual control would balance ease of operation with the desires of the community.

\subsubsection{Degree of commercialization}

Along with CAPEX and OPEX, a realistic and accurate economic evaluation for a desalination system must include the level of commercialization of the technology. The cost of a technology drops significantly as the number of units produced, sold and installed increases. Among the technologies discussed here, $\mathrm{RO}$ has been commercialized since the 1960 s and has been widely adopted and used. A significant reason for the advancement of RO technology was the US government's research funding and support for the technology throughout the 1960 s and 1970 s. $^{81}$ In comparison, $\mathrm{mCDI}$ is a new technology that is in early stages of development, with only a handful of companies commercializing the approach and little to no sustained government funding beyond academic research grants.

Currently, RO stands out as the most advanced, robust and commercially available desalination option. In $2013,71 \%$ of all desalinated water in the world was treated with RO. ${ }^{82}$ This trend is consistent in India, where in 2009 an assessment of the desalination market found that $63 \%$ of desalinated water was treated by RO. ${ }^{83}$ The widespread use of RO provides easier access to replacement parts than to those for less widely adopted $\mathrm{mCDI}$ and EDR technologies.

\section{The main issue for mCDI and EDR is that they are not mass-produced and have not been optimized in the way that RO has. A technology review of mCDI in 2013 found that in terms of capital cost an 'RO system capable of treating $1,000 \mathrm{~L} / \mathrm{h}$ costs between $\$ 3,000$ and $\$ 4,000$ whereas a similar capacity $\mathrm{mCDI}$ system costs about $\$ 10,000,{ }^{84}$}

The review suggested that this was just the current state of affairs and that in the future mCDI may become more cost-competitive. It stated: 'No components in $\mathrm{mCDI}$ apart from the membranes are expensive; today's high costs are due to low manufacturing volumes and immature manufacturing processes. ${ }^{185}$ The situation is similar for ED/EDR. Thus, it is possible in the future that charge-based technologies will receive extra financial support, either from government or private investors, allowing manufacturers to extend their availability and adoption. 


\section{Cost of desalination: summary}

The total cost of a desalination facility is broken down into capital expenditure (CAPEX) and operational expenditure (OPEX). Both CAPEX and OPEX are highly dependent on the location of the treatment facility, and vary considerably for small-scale systems. OPEX is primarily dependent on energy costs, which can be reduced by using charge-based technologies instead of $\mathrm{RO}$ for low-salinity brackish water desalination $(<3,500 \mathrm{ppm})$ or by powering the facility using renewable energy sources. Since $\mathrm{RO}$ is a more mature technology than $\mathrm{mCDI}$ and EDR, it has lower CAPEX, and it dominates the current desalination market. Solar-powered $\mathrm{RO}$ involves a costlier initial investment than grid-powered $\mathrm{RO}$, but it has greatly reduced operating expenses. Both EDR and $\mathrm{mCDI}$ have lower brine disposal and replacement costs due to their high water recovery rates and the longer lifetime of membranes, which makes them more attractive for communities that do not want to pay significant reoccurring costs. In terms of cost, the decision about which technology to choose should be based on the community's ability to invest (CAPEX) and its ability to sustainably operate and maintain the facility (OPEX). 


\section{COMMUNITY-SCALE DESALINATION FACILITIES}

There are numerous examples of field studies, pilot plants and community-scale desalination facilities based on the four main technologies discussed in this report. These examples range from academic research reviews to functioning community-scale facilities. This section is dedicated to five different case studies that were chosen either because they are successful models or failed examples, both of which provide valuable lessons to learn from. Universal to all the examples is their strategic partnerships with manufacturers and financers, necessary to build, operate, and maintain any community-scale desalination facility.

\subsection{SOLAR-POWERED

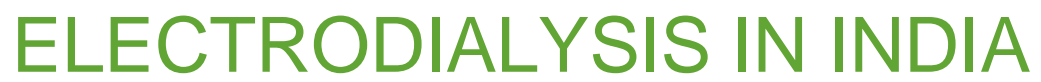

- Contact agency: Massachusetts Institute of Technology (MIT) and Tata Projects

- Source water salinity: 1,800 ppm

- Installed capacity: 500LPH

- Water recovery rate: Not reported

- Energy use: $\sim 0.8 \mathrm{kWh} / \mathrm{m}^{3}$

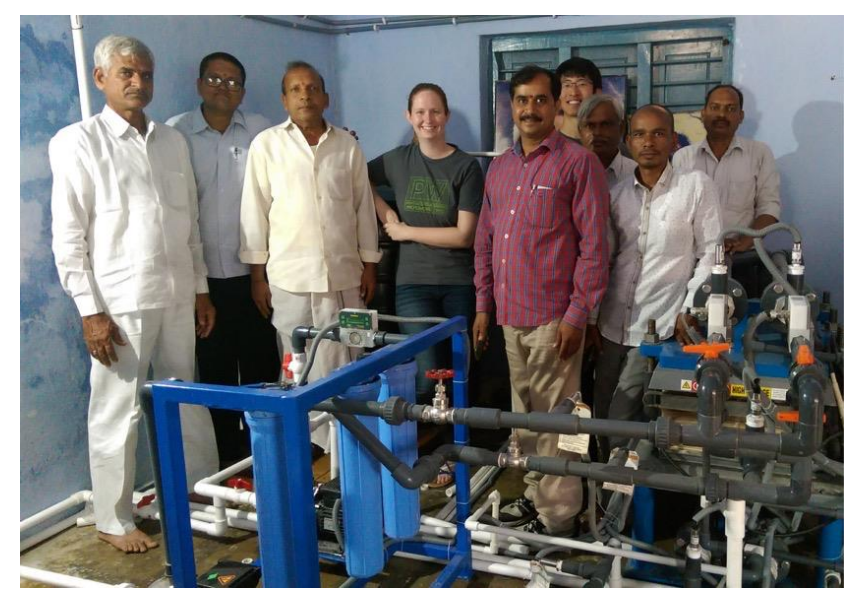

Figure 15: The Tata Projects and MIT team with their direct solar-powered ED pilot facility in Chelluru, India. Photo: Prof. Amos Winter, Department of Mechanical Engineering, MIT

In 2015, researchers at the Global Engineering and Research (GEAR) Lab at MIT, USA partnered with Tata Projects to bring community-scale solar-powered ED units to off-grid communities in India. They have one operational system in Chelluru, India and another that was due to be installed by the end of 2017 in Gaza in the Middle East. The ED units themselves were supplied by General Electric of Canada. One of the facilities is fully automated, while the other 
was designed to be partially manual in order to accommodate user preferences and to gauge to what extent local operators could run the system.

Two of their biggest challenges in marketing ED in India have been finding local vendors that can supply the necessary components and finding NGOs that are not risk-averse and are willing to test a new technology in place of the widely-used RO. The team is currently looking at ways to reduce the amount of membrane area and to optimize operation of the solar power source. They predict that their ED facility will use $75 \%, 50 \%$ and $25 \%$ less energy to treat brackish water sources of $1,000,2,000$ and $3,000 \mathrm{ppm}$ respectively than currently used RO facilities. Solarpowered ED is still in the R\&D and optimization stage. ${ }^{86}$

\subsection{MEMBRANE CAPACITIVE DEIONIZATION IN INDIA}

- Contact agency: AquaSphere/ldropan/InnoDI

- Source water salinity: Maximum of 2,000 ppm

- Installed capacity: $1-10 \mathrm{~m}^{3} / \mathrm{day}$

- Water recovery rate: $80 \%$

- Energy use: $\sim 0.8 \mathrm{kWh} / \mathrm{m}^{3}$

(a)

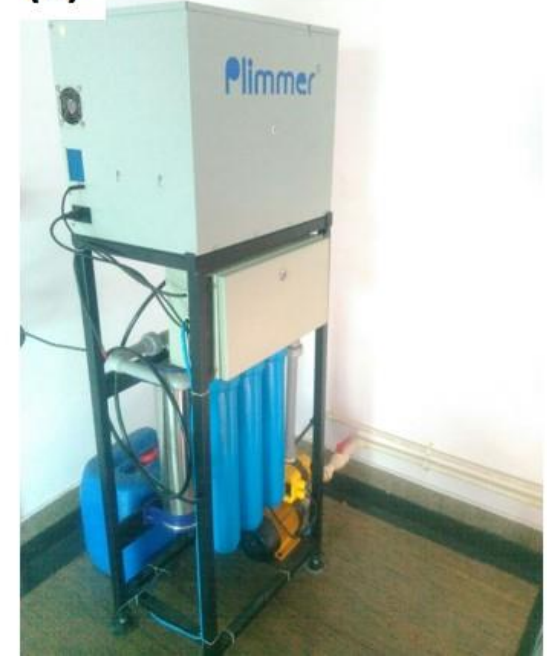

(b)

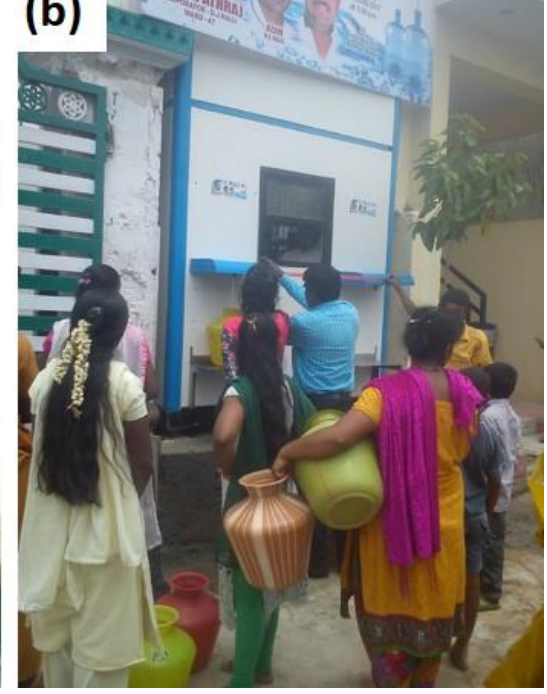

Figure 16: Idropan's mCDI technology: a) Idropan/AquaSphere Plimmer mCDI unit in an Indian hostel; b) community members collecting water from a Plimmer kiosk outside a mosque.

Photos: Vijay Sampath, director of InnoDI Water Technologies Pvt. Ltd

Idropan Dell'Orto of Italy has been working on mCDI technology since 2004. In the beginning, it was looking for alternatives to $\mathrm{RO}$ that had high water recovery rates and low energy consumption for brackish water treatment and which produced non-deionized water. It considered both EDR and $\mathrm{mCDI}$, but the high cost of the Ti electrodes used in EDR compared with the inexpensive carbon electrodes in $\mathrm{mCDI}$ led it to focus on developing $\mathrm{mCDI}$ technology. By partnering with local Indian company AquaSphere in 2012, it has successfully brought its Plimmer 
CDI units to India. There are currently $150 \mathrm{mCDI}$ units in India and Idropan has plans to expand to markets in Nepal, Ethiopia and other areas in Africa. Idropan and AquaSphere have also recently partnered with IIT Madras to form a new joint venture company, InnoDI, with the goal of mass-manufacturing $\mathrm{mCDI}$ units in India.

\subsection{SOLAR-POWERED REVERSE OSMOSIS IN INDIA}

- Contact agency: Barefoot College

- Source water salinity: Maximum 4,000 ppm

- Installed capacity: $3.6 \mathrm{~m}^{3} /$ day

- Water recovery rate: $50 \%$

- Energy use: Not reported
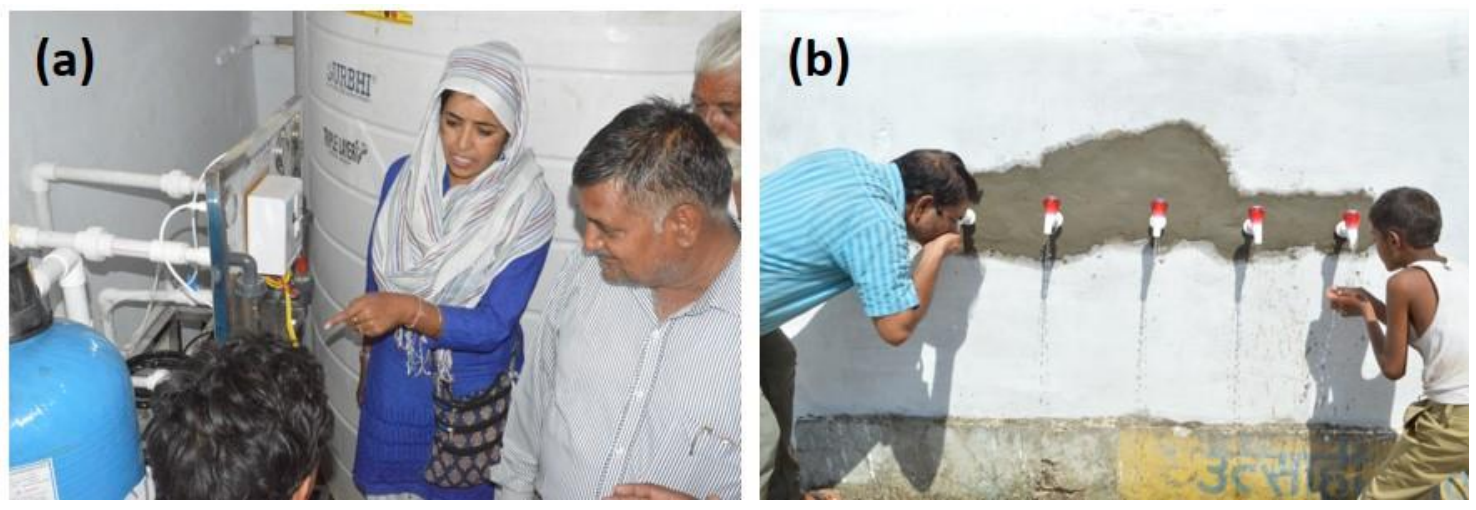

Figure 17: The Barefoot College's solar-powered RO unit in a village near Sambhar Salt Lake, Rajasthan, India: (a) local woman explaining the water purification process; (b) a village drinking fountain being supplied by PV-RO.

Photo: Dadi Jaswanth, Water Intern at Barefoot College

In 2006 the Barefoot College installed the first solar-powered RO unit in India, in the Sambhar Salt Lake region of Rajasthan. Since then the NGO has installed five more units, each supporting around 1,000 people. Not only does the Barefoot College work with the community to install the units, it also supports long-term sustainable operation by encouraging community ownership of the facility. This is done in a number of ways, including helping to establish water committees consisting entirely of community members, which are responsible for ensuring that the plant stays operational, and teaching interested community members the technical skills necessary to operate and maintain the facilities. In its business model, the water committees are in charge of pricing the water and collecting fees from community members. These fees are in turn used to pay for the replacement parts and labour required to operate and maintain the plant. Typically, a family pays around Rs. 50 per month (less than $\$ 1$ ) and is allowed to use up to $50 \mathrm{~L}$ of treated water each day. The Barefoot College plans to continue expanding the model to reach many more communities that suffer from freshwater shortages but have access to abundant amounts of brackish water. ${ }^{87}$ One of the bigger challenges for these facilities is their high capital cost, which makes them unattractive to investors and has slowed the expansion process. 


\subsection{SOLAR STILL DISTILLATION IN BANGLADESH}

- Contact agency: Oxfam

- Source water salinity: 3,000-6,000 ppm

- Installed capacity: 8-15L/day

- Water recovery rate: $13-25 \%$

- Energy use: Not reported

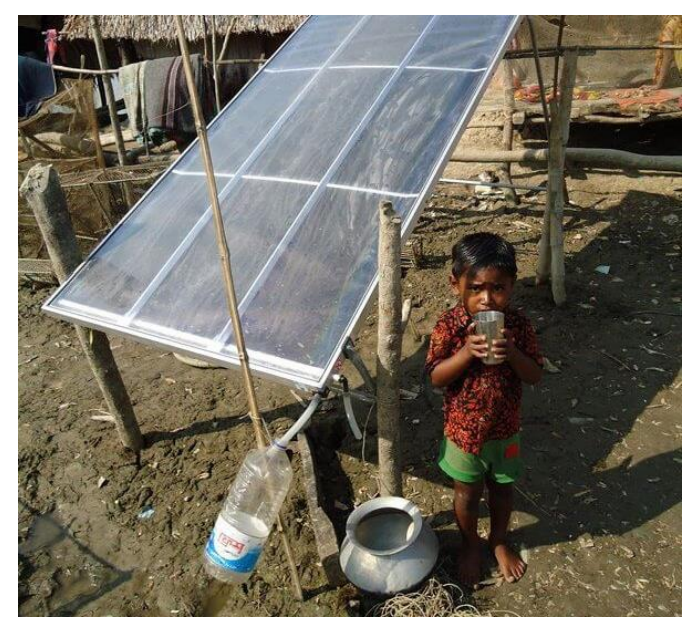

Figure 18: Child standing next to a Carocell 3000 SSD unit.

Photo: Alistair McCaskill

In 2013 Oxfam piloted two Carocell 3000 solar still units in the coastal Noakhali district of Bangladesh. The single household-size units were installed at two different households. After extensive testing, it was shown that they could provide good-quality potable water but in insufficient quantity, at just $8-15 \mathrm{~L} /$ day. Of course, it is possible to install more units to increase the overall output, but this would require extensive amounts of land and capital investment ( $\$ 450$ per unit) in order to produce sufficient water for a small community $\left(1-10 \mathrm{~m}^{3} /\right.$ day $)$. The combination of low output and high capital cost makes SSD the most expensive commercially available desalination technology in terms of price per litre of treated water. Overall, the facility was deemed not to be feasible for the specific community due to its high per household cost, minimal water output and large land requirement.

\subsection{WAVE-POWERED REVERSE OSMOSIS IN PUERTO RICO}

- Contact agency: University of Delaware

- Influent salinity: 35,000 ppm

- Plant capacity: $6.8 \mathrm{~m}^{3} / \mathrm{day}$

- Water recovery rate: Not reported

- Energy use: Not reported 
Developed in the 1980s at the University of Delaware, this seawater desalination system, known as the Delbuoy, was designed to use ocean waves to directly power a small RO unit. The system was meant for small rural communities located on the coast with little to no pre-established infrastructure but with abundant ocean water and consistent swells. Even though the system was successfully piloted in Puerto Rico and was shown to work, it was never fully commercialized. A graduate student working on the project at the time cited a few key reasons as mismanagement by the company that licensed the technology; the loss of all equipment during a hurricane; and the inability of team members to fully dedicate themselves to the project due to conflicting life developments. ${ }^{88}$ Poor management decisions and unforeseen environmental conditions are common failure points in bringing any new technology to scale and are not a reflection of the feasibility of the particular technology.

\section{Community-scale desalination facilities: summary}

In general, this brief collection of examples highlights that there exist alternatives to widely used grid-powered RO for low-income communities: either off-grid RO powered by renewable sources or emerging alternatives to RO such as EDR, SSD and mCDI.

The Barefoot College has reproducibly demonstrated the technical and economic feasibility of solar-powered $\mathrm{RO}$ at community scale. However, the low water recovery rate (around $50 \%$ ) of its single-pass RO facilities in water-stressed Rajasthan is not ideal, and it is exploring the possibility of installing more water-efficient technologies such as mCDI. In fact, there is growing interest in mCDI across India. Thus far, AquaSphere and Idropan have installed over $100 \mathrm{mCDI}$ facilities and, with IIT Madras, have established InnoDI, a joint venture company that is working towards manufacturing the units locally, which would further reduce their cost and increase their availability.

There are early-stage pilot demonstrations, such as the solar-powered ED installations trialed by MIT and Tata Projects, that hold great promise as viable options for community-scale facilities down the road. As of yet, however, these have not been commercialized.

The Carocell SSD unit tested in Bangladesh was deemed to be too expensive for rural communities, given its low water production rate of $8-15 \mathrm{~L} /$ day. That said, it is a proven technology, and may still be an option for very small communities that need only tens of litres of water a day and have abundant land and solar resources.

Wave powered RO was tested in Puerto Rico but was never successfully commercialized. In this case, poor management decisions and unforeseen environmental conditions were failure points which are not uncommon failure points in bringing any new technology to scale. This is not a reflection of the feasibility of the technology but it is useful to keep in mind in order to increase the likelihood of success with a community scale desalination facility.

For further investigation, several other examples of desalination feasibility studies are listed in Table 7 below. 
Table 7: Additional desalination feasibility studies

\begin{tabular}{|c|c|c|}
\hline Project & Year & Reference \\
\hline $\begin{array}{l}\text { CDI in rural } \\
\text { Australia }\end{array}$ & 2013 & $\begin{array}{l}\text { M. Mossad, W. Zhang and L. Zou (2013). Using capacitive } \\
\text { deionisation for inland brackish groundwater desalination in a } \\
\text { remote location. Desalination 308, 154-160. }\end{array}$ \\
\hline $\begin{array}{l}\text { CDI technology } \\
\text { review }\end{array}$ & 2012 & $\begin{array}{l}\text { S. Porada, R. Zhao, A. van der Wal, V. Presser and P.M. } \\
\text { Biesheuvel (2013). Review on the science and technology of water } \\
\text { desalination by capacitive deionization. Progress in Materials } \\
\text { Science } 58,1388-1442 \text {. }\end{array}$ \\
\hline $\begin{array}{l}\text { Solar-powered } \\
\text { EDR feasibility } \\
\text { study }\end{array}$ & 2015 & $\begin{array}{l}\text { C. Fernandez-Gonzalez, A. Dominguez-Ramos, R. Ibanez and A. } \\
\text { Irabien (2015). Sustainability assessment of electrodialysis powered } \\
\text { by photovoltaic solar energy for freshwater production. Renewable } \\
\text { and Sustainable Energy Reviews } 47,604-615 \text {. }\end{array}$ \\
\hline $\begin{array}{l}\text { Solar stills } \\
\text { technology } \\
\text { review } 33\end{array}$ & 2016 & $\begin{array}{l}\text { D.D.W. Rufuss, S. Iniyan, L. Suganthi and P.A. Davies (2016). Solar } \\
\text { stills: A comprehensive review of designs, performance and material } \\
\text { advances. Renewable and Sustainable Energy Reviews 63, 464- } \\
496 .\end{array}$ \\
\hline $\begin{array}{l}\text { Wave-powered } \\
\text { RO in India }\end{array}$ & 2004 & $\begin{array}{l}\text { N. Sharmila, P. Jalihal, A.K. Swamy and M. Ravindran (2004). } \\
\text { Wave powered desalination system. Energy 29, 1659-1672. }\end{array}$ \\
\hline $\begin{array}{l}\text { Solar-powered } \\
\text { RO and diesel } \\
\text { RO comparison } \\
\text { study }\end{array}$ & 2011 & $\begin{array}{l}\text { A.M. Bilton, R. Wiesman, A.F.M. Arif, S.M. Zubair and S. Dubowsky } \\
(2011) \text {. On the feasibility of community-scale photovoltaic-powered } \\
\text { reverse osmosis desalination systems for remote locations. } \\
\text { Renewable Energy } 36,3246-3256 \text {. }\end{array}$ \\
\hline $\begin{array}{l}\text { Wind RO in } \\
\text { Vietnam } \\
\text { feasibility } \\
\text { study }{ }^{30}\end{array}$ & 2010 & $\begin{array}{l}\text { H.T. Nguyen and J.M. Pearce (2010). Renewable Powered } \\
\text { Desalination In The Coastal Mekong Delta. American Society of } \\
\text { Mechanical Engineers. }\end{array}$ \\
\hline
\end{tabular}




\section{CONCLUSION AND RECOMMENDATIONS}

\section{Selecting the appropriate desalination technology}

This report broadly organizes existing desalination technologies into three categories based on their fundamental operating principles: thermal, membrane and charge-based. Within these categories there are various commercially available as well as early-stage emerging technologies (see section 2). By evaluating each option based on its technical and financial suitability for small rural communities needing $1-10 \mathrm{~m}^{3}$ of fresh water daily, this report focused on four technologies: reverse osmosis $(\mathrm{RO})$, membrane capacitive deionization ( $\mathrm{mCDI}$ ), electrodialysis reversal (EDR), and solar still distillation (SSD).

All of these technologies have been successfully demonstrated to consistently reduce salinity to a healthy range for drinking and all are commercially available. They can all be automated to meet users' needs and are available in varying output capacities, including systems with an output of $1-10 \mathrm{~m}^{3} /$ day. Deciding which technology is appropriate for a specific community depends primarily on the following factors: salinity of available water source, access to capital, available energy sources, available technical capacity for operation and maintenance, concern for environmental damage, willingness to take risks with new technologies and local availability of the technology and associated replacement parts. Table 8 and Figure 19 provide a summary of information to help determine which of the four technologies may be best suited for a given community.

Table 8: Comparing RO, mCDI, EDR and SSD technologies discussed in this report

\begin{tabular}{|c|c|c|}
\hline Technology & Benefits & Considerations \\
\hline RO & $\begin{array}{l}\text { - Commercially mature } \\
\text { technology: } \\
\circ \text { Widely available } \\
\circ \text { Easy access to } \\
\text { replacement } \\
\text { parts } \\
\circ \quad \text { Reduced capital } \\
\text { cost } \\
\text { - Energy-efficient for } \\
\text { seawater desalination, but } \\
\text { can also be used for inland } \\
\text { brackish water }\end{array}$ & $\begin{array}{l}\text { - Low water recovery rate: } \\
\quad \circ \quad \text { Single-pass }(25-50 \%) \\
\circ \quad \text { Multi-pass }(\sim 80 \%) \\
\text { - } \quad \text { Extensive pre-treatment and } \\
\text { maintenance needs } \\
\text { - Large waste volumes and associated } \\
\text { environmental impact } \\
\text { - RO membranes are sensitive to chlorine }\end{array}$ \\
\hline
\end{tabular}




\begin{tabular}{|c|c|c|}
\hline $\mathrm{mCDI}$ & $\begin{array}{l}\text { - High water recovery }(85- \\
90 \%) \\
\text { Energy-efficient for brackish } \\
\text { water desalination }(<3,500 \\
\text { ppm) } \\
\text { Reduced environmental } \\
\text { impact compared with } \mathrm{RO}\end{array}$ & 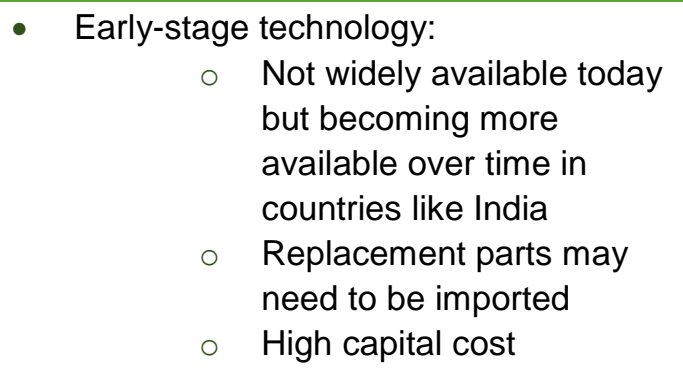 \\
\hline EDR & $\begin{array}{l}\text { - High water recovery }(85- \\
90 \%) \\
\text { Energy-efficient for brackish } \\
\text { water desalination }(<3,500 \\
\text { ppm) } \\
\text { Reduced environmental } \\
\text { impact compared with } \mathrm{RO}\end{array}$ & $\begin{array}{l}\text { Mature technology but optimized for } \\
\text { industrial processes: } \\
\circ \text { Not widely available for drinking } \\
\text { water treatment } \\
\circ \quad \text { Replacement parts may need to be } \\
\text { imported } \\
\circ \quad \text { High capital cost }\end{array}$ \\
\hline SSD & $\begin{array}{l}\text { - } \quad \text { Simple design } \\
\text { - } \quad \text { Low maintenance and } \\
\text { operational costs } \\
\text { - } \quad \text { Minimal environmental } \\
\text { impact } \\
\text { - Can be used for both } \\
\text { seawater and brackish } \\
\text { water desalination }\end{array}$ & $\begin{array}{l}\text { - } \text { Large land requirement } \\
\text { - } \quad \text { Low output volumes } \\
\text { - } \text { Output dependent on weather } \\
\text { - High capital cost }\end{array}$ \\
\hline
\end{tabular}




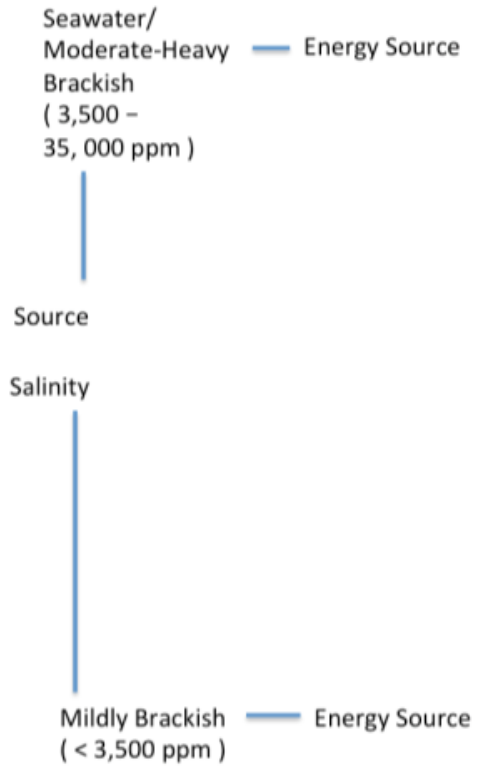

\section{Legend}

Low

Low-moderate

Moderate

High

Split: inland v coastal
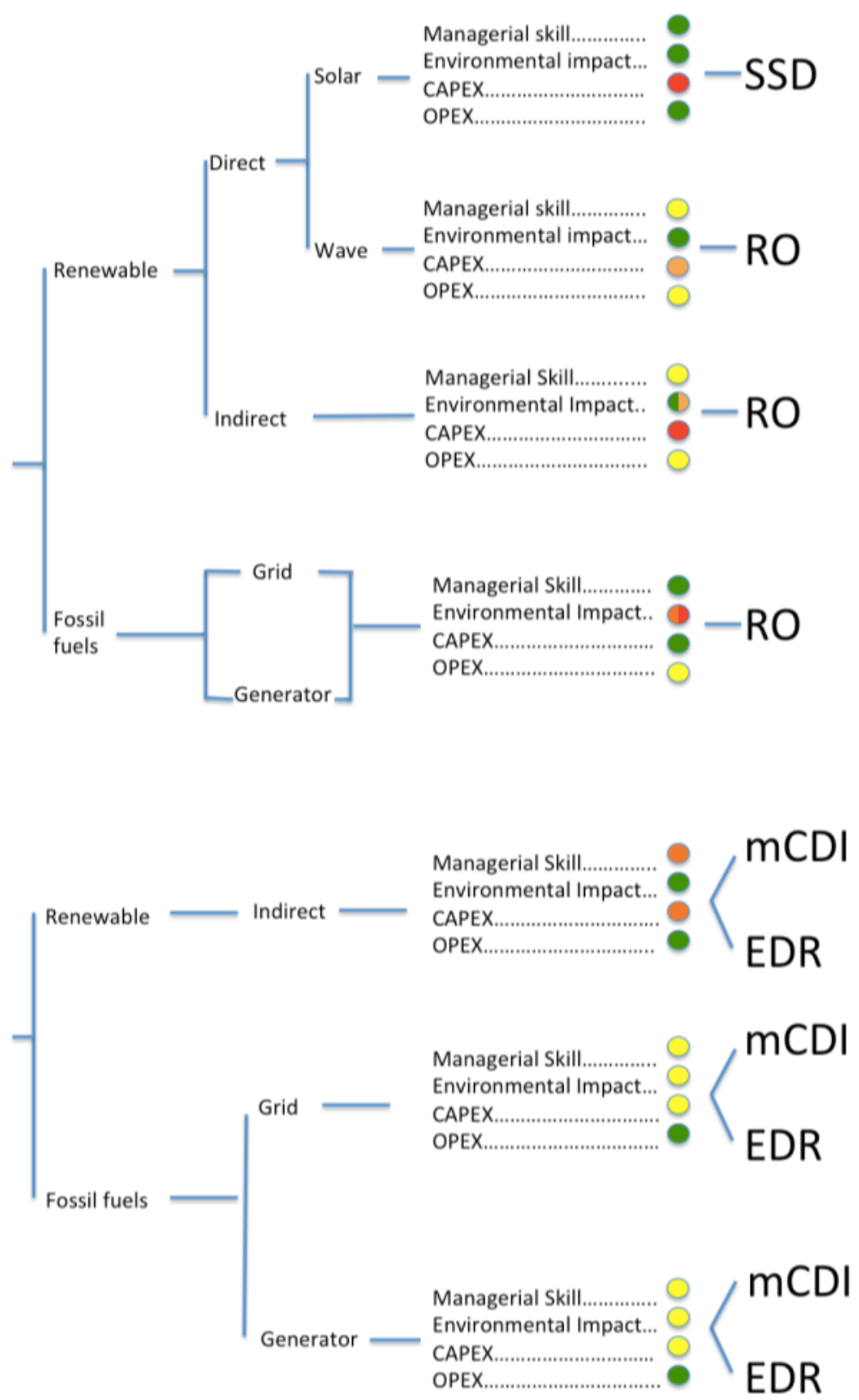

Figure 19: A guide to assist technology choices

This guide is based on source water salinity, available energy sources, managerial skills, environmental considerations and access to capital. Note that direct renewable energy means that there is no conversion step necessary: thermal energy from the sun or wave energy from the ocean can be used directly without converting it to electrical energy to power the desalination system. An indirect system requires the original energy source to be converted into electrical energy and is inherently less energy-efficient than direct use of the energy source. 
This decision guide is useful in terms of providing a general overview of when a specific technology may be preferable. The grading scale, of low, low-moderate, moderate and high, is meant to be relative, comparing the different options against one another. For example, a renewable-powered $\mathrm{RO}$ unit can have a capital cost of around $\$ 20,000-\$ 80,000$ (designated as red - high) while a grid-powered $R O$ unit of the same size costs between $\$ 4,000$ and $\$ 8,000$ (designated as low - green). All other factors listed in the guide - managerial skill, environmental impact and OPEX - also follow this relative scale.

EDR and $\mathrm{mCDI}$ technologies are in the early stages of commercialization, which is reflected in their wide ranges of capital cost. However, in general $\mathrm{MCDI}$ and EDR are likely to be twice as expensive as conventional RO units, with significant additional costs if they are powered by renewable energy sources. On the other hand, while SSD has minimal to no operating costs, it has a very high capital cost per litre due to its very low daily output rate, making the technology less attractive for low-income rural communities.

\section{Technology limitations}

The decision guide provides only relative grading for the technologies and does not list specific limitations. Since this information is useful, key considerations for each of the technologies are discussed below:

- Reverse osmosis: RO units have low water recovery rates, between $25 \%$ and $80 \%$ (single pass and multi-pass), which means that between $75 \%$ and $20 \%$ of the feed water is rejected as waste brine. For communities with large water supplies and sufficient financial resources to pay for the safe disposal of waste brine, this is not a huge issue. For example, coastal communities have the entire ocean as a source and can find ways to appropriately dispose of waste back into the sea. However, for inland communities where there are limited amounts of groundwater and little means of appropriate disposal, the high volume of waste that is produced from $\mathrm{RO}$ can become a major concern. A second consideration with $\mathrm{RO}$ units is that they are optimised for seawater desalination but are energy-intensive for desalination of brackish water, which adds to the operating costs.

- Membrane capacitive deionization: $\mathrm{mCDI}$ is a newly commercialized technology, and the limited availability of $\mathrm{mCDI}$ units and associated replacement parts across South Asia is a concern. Further, for communities that are risk-averse, this emerging technology may not be an optimum choice as maintenance help may be limited.

- Electrodialysis reversal: EDR is much more prevalent than $\mathrm{mCDI}$ and has been widely used for industrial applications. However, the use of EDR for drinking water applications is more recent. While the technology is fairly advanced, its cost, operation and sales volumes are not optimized for widespread treatment of drinking water. Hence, similar to mCDI, it may be challenging to find replacement parts and maintenance help easily, especially for rural offgrid communities.

- Solar still distillation: SSD has very low water production volumes, with most units producing only $2-35 \mathrm{~L} /$ day, which is only enough to supply water to $1-5$ individuals. ${ }^{89} \mathrm{It}$ is possible of course to install numerous SSD facilities, but this requires excessive land area and capital investment. 


\section{Energy consumption}

When comparing technologies in terms of their energy needs, it is useful to think about the amount of energy required, as well as any limitations on the source of energy. The minimum energy requirements for desalination, regardless of the technology, are determined by the thermodynamic threshold for separating salt from water, which is a function of salinity. However, in practice, all desalination technologies require at least 2-10 times the thermodynamic threshold. The practical energy needs for a given technology depend on both the fundamental operating principles and the extent of research and development put into optimizing the process. For example, RO technology is better suited in principle for seawater desalination and has been optimized for the application, with energy consumption as low as $1.75 \mathrm{kWh} / \mathrm{m}^{3}$. For lower-salinity brackish water sources, EDR and $\mathrm{mCDI}$ technologies are more energy-efficient than RO, with reported energy consumptions of less than $1 \mathrm{kWh} / \mathrm{m}^{3}$ for salinities of less than $3,500 \mathrm{ppm}$. The energy needs of SSD are quite large and do not vary much with source salinity; however, energy values are often not reported for SSD, as energy is sourced freely and directly from the sun.

Apart from SSD, which requires solar energy, all other desalination technologies can be powered by almost any source of energy (fossil and renewable sources). The decision to utilize a renewable energy source is determined primarily by the location, but it also depends on the community's access to additional capital for installing renewable power facilities and units for energy storage and back-up, and the additional technical capacity required for maintenance.

\section{Powering a technology with renewables instead of conventional fossil fuels can double or triple capital costs, but results in much lower operating costs in the long run.}

\section{Taking risks with emerging technologies - competing with RO}

$\mathrm{RO}$ is a mature technology that has been commercialized for desalination for several decades and hence is the most widely used option today. Its widespread availability and lower cost due to economies of scale gives it several advantages over newer technologies such as EDR and mCDI.

- Capital costs are typically much lower than for the less mature EDR and mCDI technologies.

- Equipment manufacturers and suppliers are globally available, while suppliers of EDR, $\mathrm{mCDI}$ and SSD technology are currently limited to certain regions of the world.

- Consumers are aesthetically accustomed to water produced by RO, which is particularly low in salinity $(<100 \mathrm{ppm})$. SSD also produces very low-salinity drinking water, but both EDR and $\mathrm{mCDI}$ are optimized for an output of 200-400 ppm. EDR and mCDI can be designed to produce very low-salinity water, but this may involve additional capital or operational cost.

- Most NGOs have experience and expertise with RO alone. In many cases staff and project leads are not even aware of alternative technology options.

That said, there are circumstances where alternative options outperform RO. In particular $\mathrm{RO}$ is wasteful, a single pass system converts only around $25-50 \%$ of feed water into drinking water. This low water recovery rate has been shown to be improved, to up to $80 \%$, if a multi-pass system is used, which means re-treating the brine stream to make it fresh. However, the multipass system can double the energy use of the system, subsequently adding to OPEX, which is 
less desirable. In comparison, when operated properly, EDR and mCDI have shown recovery rates of up to $85-90 \%$.

\section{With minimal brine production and considerably less energy use, EDR and mCDI are set up to be much more desirable technologies for inland brackish water treatment than RO.}

The desire to have technologies with higher water recovery capabilities is highlighted by a recent legal action pursued by Indian NGOs through the National Green Tribunal against water wastage from RO facilities..$^{90}$ These kinds of value shifts, led by extreme water stress and/or governmental regulation, are making alternative technologies to $\mathrm{RO}$ more and more attractive.

For communities interested in non-RO technologies, the choice between $\mathrm{mCDI}$ and EDR, with their similar performance metrics, may not be obvious; the following are some distinguishing factors. EDR is a much more mature technology compared with $\mathrm{mCDI}$ and was originally designed and optimized for industrial applications involving separation for the concentration of solutes (e.g. fruit juice concentrates). Although EDR units have been manufactured and sold by multinational companies such as GE, their use for water treatment has been limited to RO posttreatment for high-purity water in industrial settings (e.g. silicon wafer manufacturing). Even though the technology itself is available globally, the cost and robustness of EDR have not been optimized for widespread treatment of drinking water. mCDI, on the other hand, is a more recent technology that was developed specifically for drinking water treatment. However, as a new technology, there are few mCDI demonstration facilities available to assess the robustness and lifetime of the technology in the field.

\section{Overall recommendations}

\section{Of the four technologies examined in detail, Oxfam's overall}

recommendation for seawater and brackish water desalination is RO, because it is the most widely commercialized, least expensive and most technically researched and optimized option.

$\mathrm{RO}$ units have been shown for decades to work at various scales and involve the least amount of failure risk. Further, the technology has reached economies of scale, so the costs of a small system and replacement parts are likely to be lower than those for similar-sized emerging technology alternatives (including $\mathrm{mCDI}$, EDR and SSD). The widespread use and adoption of $\mathrm{RO}$ technology also improves the chances of finding technical expertise for maintenance locally. It should be noted that global sales and demand for RO technology have led to manufacturing and sales of membranes of varying quality, which results in drastic differences in water recovery (from less than $25 \%$ to $50 \%$ ) in RO facilities. Generally, lower-priced membranes are of lower quality and have lower water recovery abilities. So, investing in higher-quality membranes and/or multi pass systems can help reduce water waste and make $\mathrm{RO}$ more environmentally friendly and water-efficient.

If an alternative to RO is highly desired, $\mathrm{mCDI}$ is recommended for lowsalinity $(<3,500 \mathrm{ppm})$ brackish water sources because it has low energy consumption, is inexpensive to produce and, in India at least, there are plans to mass-manufacture mCDI units. 
The next steps for anyone interested in installing a desalination unit in South Asia are (1) understanding the specific constraints faced by the community involved, (2) using these constraints to navigate the decision guide to identify the most suitable technology and (3) following up by contacting relevant technology suppliers.

Finding reliable suppliers can be a challenge. To assist those looking for suppliers of desalination units, the Appendix contains contact information for some of the companies that the authors interacted with in the process of preparing this report. The table is by no means an exhaustive list and is limited to companies that expressed interest in being included in the report. Inclusion in the table does not necessarily signify the quality or performance of any particular product. 


\section{APPENDIX}

\section{Suppliers of desalination technology and NGOs and social enterprises with experience in using it}

Table 1: Suppliers of desalination technologies in South Asia

\begin{tabular}{|c|c|c|c|}
\hline Technology & $\begin{array}{l}\text { Company } \\
\text { (home country) }\end{array}$ & Notes & Contact info \\
\hline RO & $\begin{array}{l}\text { Aquvio } \\
\text { (India) }\end{array}$ & $\begin{array}{l}\text { Based in Varanasi, India, this start-up was } \\
\text { established in } 2015 \text { with the goal of reducing RO } \\
\text { waste by increasing water recovery. By } 2016 \text { it } \\
\text { was providing potable drinking water to } 50,000 \\
\text { people, } 20,000 \text { of them students. The company } \\
\text { has two different units, one that can produce } \\
\text { water at } 50 \mathrm{LPH} \text { and the other at } 100 \mathrm{LPH} \text {. The } \\
\text { advantages of this RO unit are that it is locally } \\
\text { manufactured; it produces water at a locally } \\
\text { affordable price (Rs } 0.29 / \mathrm{L}=\text { less than } \$ .01 / \mathrm{L} \text { ); } \\
\text { and it has a high water recovery rate for RO } \\
\text { (around } 70 \% \text { ). }\end{array}$ & $\begin{array}{l}\text { Representatives reachable via } \\
\text { contact form on website: } \\
\text { www.aquvio.com }\end{array}$ \\
\hline $\mathrm{RO}$ & $\begin{array}{l}\text { Tata Projects } \\
\text { (India) }\end{array}$ & $\begin{array}{l}\text { Tata Projects, the infrastructure wing of the Tata } \\
\text { Group, an Indian multinational conglomerate, } \\
\text { offers a line of water purifiers. Its TQ units are } \\
\text { available in capacities of } 200-1,000 \mathrm{LPH} \text { and are } \\
\text { designed to address the drinking water needs of } \\
\text { rural communities. The company currently has } \\
2,500 \text { plants operating in rural India, with the } \\
\text { majority of them being powered by the grid. The } \\
\text { units are designed to purify water with influent } \\
\text { TDS of between } 1,000 \text { and } 3,000 \text { ppm. } \\
\text { Tata Projects has worked extensively with local } \\
\text { NGOs and financial providers in India to ensure } \\
\text { the long-term sustainability of its units. Through } \\
\text { its successful social entrepreneurship model, it } \\
\text { consistently provides potable water at a locally } \\
\text { affordable price of Rs. } 5 \text { per } 20 \mathrm{~L} \text { ( } \$ .08 / 20 \mathrm{~L} \text { ). The } \\
\text { company's desalination facilities are limited to } \\
\text { India, but it is keen to expand to markets in } \\
\text { Bangladesh, Sri Lanka, countries in Northern } \\
\text { Africa and elsewhere. }\end{array}$ & $\begin{array}{l}\text { Email: } \\
\text { tpl@tataprojects.com } \\
\text { Phone: } \\
\text { +91040 } 66238801 \\
\text { www.tataprojects.com }\end{array}$ \\
\hline
\end{tabular}




\begin{tabular}{|c|c|c|c|}
\hline $\begin{array}{l}\text { Solar- } \\
\text { powered RO }\end{array}$ & $\begin{array}{l}\text { Boreal Light } \\
\text { (Germany) }\end{array}$ & $\begin{array}{l}\text { Boreal Light GmbH builds and sells solar- } \\
\text { powered desalination and filtration systems. Its } \\
\text { RO unit, the Winture Planet-Cube ASW/ABW, is } \\
\text { designed to operate as an independent off-grid } \\
\text { facility, requiring no diesel generator or grid } \\
\text { connections. The unit itself is simple to operate, } \\
\text { and Boreal carries out } 24 / 7 \text { remote monitoring of } \\
\text { all mechanical and electrical components from } \\
\text { Germany. The Winture unit has capacities } \\
\text { ranging from } 150 \text { to } 10,000 \mathrm{LPH} \text { and can be } \\
\text { used for brackish water and seawater } \\
\text { desalination, for either drinking or irrigation } \\
\text { purposes. The company is based in Germany } \\
\text { but is currently looking to partner with dealers in } \\
\text { Asia, Africa, South America and the Middle East. }\end{array}$ & $\begin{array}{l}\text { Hamed Beheshti } \\
\text { (Executive Manager) } \\
\text { Email: } \\
\text { beheshti@boreallight.com } \\
\text { Phone: } \\
\text { +49 } 17670924068 \\
\text { www.winture.de }\end{array}$ \\
\hline $\begin{array}{l}\text { Solar- } \\
\text { powered RO }\end{array}$ & $\begin{array}{l}\text { Trunz Water } \\
\text { Systems } \\
\text { (Switzerland) }\end{array}$ & $\begin{array}{l}\text { Trunz Water Systems is a Swiss company that } \\
\text { develops, manufactures and distributes solar- } \\
\text { and wind-powered desalination units. It offers } \\
\text { RO units capable of treating both brackish water } \\
\text { and seawater for long-term sustainable use or in } \\
\text { disaster relief situations; its units can treat } 6- \\
60 \mathrm{~m}^{3} / \text { day. The company has been supplying } \\
\text { water technologies since } 2003 \text { and has over } 950 \\
\text { facilities across } 35 \text { countries, including India, } \\
\text { Nepal, Malaysia and Indonesia. }\end{array}$ & $\begin{array}{l}\text { René Hauser } \\
\text { (Director Sales and Marketing) } \\
\text { Email: } \\
\text { r.hauser@trunz.ch } \\
\text { Phone: } \\
+41(0) 714478540 \\
\text { www.trunzwatersystems.com }\end{array}$ \\
\hline $\begin{array}{l}\text { Solar- } \\
\text { powered RO }\end{array}$ & $\begin{array}{l}\text { Swiss Fresh } \\
\text { Water } \\
\text { (Switzerland) }\end{array}$ & $\begin{array}{l}\text { Swiss Fresh Water (SFW) was founded in } 2008 \text {, } \\
\text { and in } 2011 \text { began installing and maintaining } \\
140 \text { RO facilities in Senegal. The units can be } \\
\text { powered by the grid, by solar cells or by a hybrid } \\
\text { combination of grid and solar. Each RO unit can } \\
\text { produce } 4,000 \mathrm{~m}^{3} / \text { day of clean water from } \\
\text { brackish water, at a maximum source salinity of } \\
7,000 \text { ppm. Along with the RO unit, SFW offers } \\
\text { installation services, technical training courses } \\
\text { and kiosk management courses, in order to } \\
\text { encourage and build local maintenance and } \\
\text { managerial capacity. It started a non-profit in } \\
2012 \text {, the Access to Water Foundation (A2W), in } \\
\text { order to couple the technology with a } \\
\text { sustainable business model. In late } 2017 \text { SFW } \\
\text { began scaling up in Mauritania, Mali and } \\
\text { Guinea, along the Senegal River, and it is ready } \\
\text { to start new projects in other countries. }\end{array}$ & $\begin{array}{l}\begin{array}{l}\text { Renaud de Watteville } \\
\text { (CEO) }\end{array} \\
\text { Email: } \\
\text { rw@swissfreshwater.ch } \\
\underline{\text { info@swissfreshwater.ch }} \\
\text { Phone: } \\
+41217112277 \\
\text { www.swissfreshwater.com }\end{array}$ \\
\hline
\end{tabular}




\begin{tabular}{|c|c|c|c|}
\hline $\mathrm{RO}$ and EDR & $\begin{array}{l}\text { Evoqua } \\
\text { (USA) }\end{array}$ & $\begin{array}{l}\text { Evoqua Water Technologies is a global supplier } \\
\text { of water technologies for both wastewater and } \\
\text { drinking water applications. It mostly partners } \\
\text { with major companies active in areas such as } \\
\text { foods, beverages, power generation, } \\
\text { pharmaceuticals and petroleum. Although it } \\
\text { seems to operate more on an industrial scale, it } \\
\text { offers both EDR and RO units that can be used } \\
\text { at the scale of } 1-10 \mathrm{~m}^{3} / \text { day. Evoqua does not } \\
\text { have any offices in South Asia but it is present in } \\
\text { multiple locations in the USA, Australia, China, } \\
\text { Singapore, Canada, France, Germany, Italy, } \\
\text { Korea, the Netherlands and the UK. }\end{array}$ & $\begin{array}{l}\text { Representatives reachable via } \\
\text { contact form on website: } \\
\text { www.evoqua.com }\end{array}$ \\
\hline $\mathrm{RO}$ and EDR & $\begin{array}{l}\text { Suez/GE } \\
\text { (France/USA) }\end{array}$ & $\begin{array}{l}\text { Suez Water Technologies \& Solutions provides } \\
\text { a wide range of water treatment technologies, } \\
\text { including desalination. It offers both } R O \text { and } \\
\text { EDR units. Similar to Evoqua, the company } \\
\text { operates on a larger industrial scale, with its } \\
\text { smallest Suez } 2020 \text { EDR unit producing } \\
63.6 \mathrm{~m}^{3} / \text { hour. Despite its large output volume, } \\
\text { the technology is optimized for the treatment of } \\
\text { brackish sources with salinities ranging from } 100 \\
\text { to } 3,000 \text { ppm, and can handle up to } 12,000 \mathrm{ppm} \text {. } \\
\text { As expected, the energy consumption of these } \\
\text { EDR units is low, at only } 0.53-1.06 \mathrm{kWh} / \mathrm{m}^{3} \text {. } \\
\text { Suez's RO units are high-volume, designed for } \\
\text { industrial applications, and are unlikely to be } \\
\text { suitable for small rural communities in South } \\
\text { Asia. }\end{array}$ & $\begin{array}{l}\text { Representatives reachable via } \\
\text { contact form on website: } \\
\text { www.suezwatertechnologies.com }\end{array}$ \\
\hline EDR & $\begin{array}{l}\text { MemBrain } \\
\text { (Czech } \\
\text { Republic) }\end{array}$ & $\begin{array}{l}\text { Based in the Czech Republic, this company } \\
\text { supplies membrane technologies for a variety of } \\
\text { applications. Its EDR-X technology is ideal for } \\
\text { small-capacity desalination plants. After } \\
\text { installing EDR-X, the company trains local } \\
\text { operators on how to run the plant and provides } \\
\text { after-sales service, including site visits to } \\
\text { address major maintenance issues. It is a } \\
\text { subsidiary of Mega, a company working on } \\
\text { membrane and ion exchange-based } \\
\text { technologies for a variety of applications. }\end{array}$ & $\begin{array}{l}\text { Pavlina Kotrabata } \\
\text { (Sales and Marketing) } \\
\text { Email: } \\
\text { Pavlina.Kotrbata@membrain.cz } \\
\text { www.membrain.cz/en }\end{array}$ \\
\hline $\mathrm{mCDI}$ & $\begin{array}{l}\text { Voltea } \\
\text { (Netherlands/US } \\
\text { A) }\end{array}$ & $\begin{array}{l}\text { Founded in the Netherlands and now based in } \\
\text { the USA, Voltea is a leading supplier of mCDI } \\
\text { technology. With advances over the past few } \\
\text { years, it has been able to considerably reduce } \\
\text { the capital cost of mCDI. Its IS units are used in } \\
\text { commercial and industrial applications, while its }\end{array}$ & $\begin{array}{l}\text { Richard Bastar } \\
\text { (Sales Representative) } \\
\text { Email: } \\
\text { richard.bastar@voltea.com }\end{array}$ \\
\hline
\end{tabular}




\begin{tabular}{|c|c|c|c|}
\hline & & $\begin{array}{l}\text { DiUse unit is designed for in-home water } \\
\text { treatment. The modular design of its units allows } \\
\text { a capacity of } 1-10 \mathrm{~m}^{3} / \mathrm{day} \text { to treat brackish } \\
\text { sources with a maximum TDS of } 4,000 \mathrm{ppm} \text { for } \\
\text { drinking water in small communities. Voltea } \\
\text { currently has projects all around the world } \\
\text { including in India, Turkey and the United States. }\end{array}$ & voltea.com/en/ \\
\hline $\mathrm{mCDI}$ & $\begin{array}{l}\text { Idropan } \\
\text { Dell'Orto } \\
\text { (Italy) }\end{array}$ & $\begin{array}{l}\text { Idropan Dell'Orto is a family-owned Italian } \\
\text { company founded in } 1969 \text {. Its main line of } \\
\text { business is the design, assembly, sales and } \\
\text { maintenance of industrial and domestic water } \\
\text { purifiers. Since } 2004 \text { it has been working on } \\
\text { R\&D of mCDI. To date, the company has } \\
\text { delivered almost } 200 \text { mCDI units across } 10 \\
\text { countries worldwide (including the USA, } \\
\text { Australia, Italy, Germany, China and India). A } \\
\text { large portion of its sales has been in India, as a } \\
\text { result of close collaborations with local } \\
\text { companies such as AquaSphere (listed below). } \\
\text { In } 2016 \text {, Idropan partnered with AquaSphere } \\
\text { and the Indian Institute of Technology (IIT) } \\
\text { Madras to form a joint venture company, InnoDI } \\
\text { Water Technologies, to manufacture mCDI units } \\
\text { and expand sales in the South Indian market. }\end{array}$ & $\begin{array}{l}\text { Mariella Servida } \\
\text { (CEO) } \\
\text { Email: } \\
\text { m.servida@idropan.it } \\
\text { www.idropan.com/en/ }\end{array}$ \\
\hline $\mathrm{mCDI}$ & $\begin{array}{l}\text { AquaSphere } \\
\text { (India) }\end{array}$ & $\begin{array}{l}\text { AquaSphere is a water technologies supplier in } \\
\text { India. Along with a variety of water treatment } \\
\text { technologies, it sells Idropan's Plimmer mCDI } \\
\text { unit, which is fully automatic and can be } \\
\text { remotely managed. The company currently has } \\
150 \mathrm{mCDI} \text { facilities operating in India, with } \\
\text { capacities of } 1-20 \mathrm{~m}^{3} / \text { day. Currently all facilities } \\
\text { are grid-powered, but AquaSphere is interested } \\
\text { in installing solar-grid hybrid mCDI systems. }\end{array}$ & $\begin{array}{l}\text { Email: } \\
\text { info@aquasphere.co.in } \\
\text { Phone: }+918026535333 \\
\text { www.aquasphere.co.in }\end{array}$ \\
\hline $\mathrm{mCDI}$ & $\begin{array}{l}\text { InnoDI Water } \\
\text { Technologies } \\
\text { Pvt. Ltd. } \\
\text { (India) }\end{array}$ & $\begin{array}{l}\text { InnoDI is a new company, founded in } 2016 \text { as } \\
\text { focused on mass-manufacturing mCDI units in } \\
\text { India for global markets. The company is a joint } \\
\text { venture between Idropan, AquaSpshere and IIT } \\
\text { Madras. They are expecting to produce } 500,000 \\
\text { mCDI units annually, with capacities in the range } \\
\text { of } 1-10 \mathrm{~m}^{3} / \text { day. In order to encourage long-term } \\
\text { adoption of the technology and a sustainable } \\
\text { business model, the company works closely with } \\
\text { established local social organizations. }\end{array}$ & $\begin{array}{l}\text { Vijay Sampath } \\
\text { (Director) } \\
\text { Email: } \\
\text { vijay@innodi.in } \\
\text { www.innodi.in/ }\end{array}$ \\
\hline
\end{tabular}




\begin{tabular}{|l|l|l|l|}
\hline SSD & $\begin{array}{l}\text { F-cubed } \\
\text { (Australia) }\end{array}$ & $\begin{array}{l}\text { F-Cubed is an Australian company that offers } \\
\text { solar water treatment units worldwide. Its SSD } \\
\text { technology, Carocell, is currently available in two } \\
\text { capacities, with the Carocell 2000 unit capable } \\
\text { of producing 8-10L/day and the Carocell 3000 } \\
\text { 16-20 L/day. The company has partnered with } \\
\text { NGOs in the past, including Oxfam, with which it } \\
\text { set up a Carocell facility in Bangladesh (see } \\
\text { section 3). The units are designed to last 10-20 } \\
\text { years and require little to no maintenance. }\end{array}$ & $\begin{array}{l}\text { Representatives reachable via } \\
\text { contact form on website: } \\
\text { www.fcubed.com.au }\end{array}$ \\
& & \\
& & \\
\end{tabular}


Table 2: NGOs and social enterprises in South Asia with experience with desalination technologies

\begin{tabular}{|c|c|c|}
\hline $\begin{array}{l}\text { Organization } \\
\text { (Home country) }\end{array}$ & Notes & Contact info \\
\hline $\begin{array}{l}\text { Safe Water } \\
\text { Network } \\
\text { (India) }\end{array}$ & $\begin{array}{l}\text { Since } 2008 \text { Safe Water Network has been working in } \\
\text { Ghana and India to develop community-based safe water } \\
\text { solutions for people who are not connected to a municipal } \\
\text { water supply. In particular, its expertise includes the } \\
\text { following: providing educational programmes; installing } \\
\text { water quality and service status monitoring systems; } \\
\text { leading empowerment programmes for community leaders } \\
\text { and other NGOs; and conducting advertising campaigns to } \\
\text { activate consumer demand. In India, it is currently involved } \\
\text { in projects in Maharashtra, Telangana and Uttar Pradesh. }\end{array}$ & $\begin{array}{l}\begin{array}{l}\text { Email: } \\
\text { india@safewaternetwork.org }\end{array} \\
\text { Phone: } \\
\text { +91 126800884 } \\
\text { www.safewaternetwork.org }\end{array}$ \\
\hline $\begin{array}{l}\text { Barefoot } \\
\text { College, Tilonia } \\
\text { (India) }\end{array}$ & $\begin{array}{l}\text { The Barefoot College, is an international organization } \\
\text { working in education, skills development, healthcare, } \\
\text { drinking water, women's empowerment and electrification. } \\
\text { With regards to water, it is involved in rainwater harvesting, } \\
\text { the construction of dams, digital water mapping and } \\
\text { desalination. Its desalination work is centred in the } \\
\text { Sambhar Salt Lake area in Rajasthan, India, where it } \\
\text { currently has six solar-powered RO facilities installed (see } \\
\text { section 3). Along with its work on RO, the Barefoot College } \\
\text { has been working on piloting an mCDI unit, also in } \\
\text { Rajasthan, by the end of } 2017 \text {. It is excited by the prospect } \\
\text { of using mCDI instead of RO to increase water recovery } \\
\text { rates to } 80 \% \text {. The Barefoot College takes great interest in } \\
\text { the sustainability of its facilities and works closely with } \\
\text { communities to make sure that this happens. }\end{array}$ & $\begin{array}{l}\text { Dadi Jaswanth } \\
\text { (Project Implementation) } \\
\text { Email: } \\
\text { dadijaswanth222@gmail.com } \\
\text { www.barefootcollege.org }\end{array}$ \\
\hline $\begin{array}{l}\text { WECONNEX } \\
\text { (Switzerland) }\end{array}$ & $\begin{array}{l}\text { WECONNEX offers both consulting services and the } \\
\text { integration of technology for sustainable, decentralized } \\
\text { infrastructure development. In consulting, it provides } \\
\text { guidance on business modelling and technology and } \\
\text { market development. In technology integration, it is looking } \\
\text { to work with suitable technologies to support its NEXUS } \\
\text { concept of safe drinking water, sustainable energy, } \\
\text { sanitation and communication. The organization has } \\
\text { partnered with Trunz Water Systems and is currently } \\
\text { working on projects in Madagascar and Nepal. }\end{array}$ & $\begin{array}{l}\text { Lars Willi } \\
\text { (Founder) } \\
\text { Email: } \\
\text { lars.willi@weconnex.org } \\
\text { Phone: +41719238888 } \\
\text { http://weconnex.org/ }\end{array}$ \\
\hline
\end{tabular}


1 World Health Organization (WHO) (2017). Drinking-water. WHO Media Centre. http://www.who.int/mediacentre/factsheets/fs391/en/ (accessed 1 May 2017)

2 (WHO) (2017). Drinking-water, op. cit.

3 N.C. Wright and A.G.V. Winter (2014). Justification for community-scale photovoltaic-powered electrodialysis desalination systems for inland rural villages in India, op. cit.

4 R. Jacobsen (2016). Israel Proves the Desalination Era Is Here. Scientific American. https://www.scientificamerican.com/article/israel-proves-the-desalination-era-is-here/ (accessed 1 June 2017)

5 WHO (2003). Total dissolved solids in Drinking-water.

http://www.who.int/water_sanitation_health/dwq/chemicals/tds.pdf

6 United States Bureau of Reclamation (2003). Desalting Handbook for Planners. Desalination and Water Purification Research and Development Report \#72.

7 T. Abraham and A. Luthra (2011). Socio-economic \& technical assessment of photovoltaic powered membrane desalination processes for India. Desalination 268, 238-248.

8 WHO (2003). Total dissolved solids in Drinking-water, op. cit.

9 N.C. Wright and A.G.V. Winter (2014). Justification for community-scale photovoltaic-powered electrodialysis desalination systems for inland rural villages in India, op. cit.

10 A.E. Khan et al. (2011). Drinking Water Salinity and Maternal Health in Coastal Bangladesh: Implications of Climate Change. Environmental Health Perspectives 119, 1328-1332.

11 WHO (2011). Guidelines for Drinking-water Quality: Fourth Edition. http://apps.who.int/iris/bitstream/handle/10665/44584/9789241548151_eng.pdf

12 N.C. Wright and A.G.V. Winter (2014). Justification for community-scale photovoltaic-powered electrodialysis desalination systems for inland rural villages in India, op. cit; WHO (2011). Guidelines for Drinking-water Quality: Fourth Edition, op. cit.

13 H.J. Krishna (2004). Introduction to Desalination Technologies. https://texaswater.tamu.edu/readings/desal/introtodesal.pdf

14 N.C. Wright and A.G.V. Winter (2014). Justification for community-scale photovoltaic-powered electrodialysis desalination systems for inland rural villages in India, op. cit.; .J. Krishna (2004). Introduction to Desalination Technologies.

15 Separation Processes. Multiple-Effect Distillation. http://www.separationprocesses.com/Distillation/DT_Chp07b.htm (accessed 1 June 2017)

16 M. Al-Shammiri and M. Safar (1999). Multi-effect distillation plants: state of the art. Desalination 126, 4559.

17 H.J. Krishna (2004). Introduction to Desalination Technologies, op. cit. 
18 A. Al-Karaghouli and L.L. Kazmerski (2013). Energy consumption and water production cost of conventional and renewable-energy-powered desalination processes. Renewable and Sustainable Energy Reviews 24, 343-356.

19 H.J. Krishna (2004). Introduction to Desalination Technologies, op. cit.; Desalination. Desalination Technique I: Vacuum Distillation. https://sites.google.com/site/kjdesalination/vacuum-distillation (accessed 1 July 2017)

20 A.E. Khan et al. (2011). Drinking Water Salinity and Maternal Health in Coastal Bangladesh, op. cit.

21 World Health Organization (2011). Guidelines for Drinking-water Quality: Fourth Edition.

22 J.W. Wu, M.J. Biggs and E.J. Hu (2014). Dynamic model for the optimisation of adsorption-based desalination processes. Applied Thermal Engineering 66, 464-473.

23 A. Alkhudhiri, N. Darwish and N. Hilal (2012). Membrane distillation: A comprehensive review. Desalination 287, 2-18.

24 J. Walton et al. (2004). Solar and Waste Heat Desalination by Membrane Distillation. College of Engineering, University of Texas at El Paso. https://www.usbr.gov/research/dwpr/reportpdfs/report081.pdf

25 Ibid.

26 A. Alkhudhiri, N. Darwish and N. Hilal (2012). Membrane distillation: A comprehensive review, op. cit.

27 B.S. Lalia, V. Kochkodan, R. Hashaikeh and N. Hilal (2013). A review on membrane fabrication: Structure, properties and performance relationship. Desalination 326, 77-95.

28 M. Elimelech and W.A. Phillip (2011). The Future of Seawater Desalination: Energy, Technology, and the Environment. Science 333, 712-717.

29 lbid.

30 U. Lachish (2002). Optimizing the Efficiency of Reverse Osmosis Desalination. In New: Osmosis Desalination and Carnot, Guma Science. http://urila.tripod.com/Seawater.htm (accessed 1 July 2017)

31 M. Elimelech and W.A. Phillip (2011). The Future of Seawater Desalination: Energy, Technology, and the Environment. op. cit.

32 D. Talbot (2015). Megascale Desalination: The world's largest and cheapest reverse-osmosis desalination plant is up and running in Israel. MIT Technology Review.

https://www.technologyreview.com/s/534996/megascale-desalination/ (accessed 1 July 2017)

33 N.C. Wright and A.G.V. Winter (2014). Justification for community-scale photovoltaic-powered electrodialysis desalination systems for inland rural villages in India, op. cit.

34 M. Elimelech and W.A. Phillip (2011). The Future of Seawater Desalination: Energy, Technology, and the Environment, op. cit.

35 V.G. Gude (2011). Energy consumption and recovery in reverse osmosis. Desalination and Water Treatment 36, 239-260.

36 A. Alkhudhiri, N. Darwish and N. Hilal (2012). Membrane distillation: A comprehensive review, op. cit.

37 L.F. Greenlee, D.F. Lawler, B.D. Freeman, B. Marrot and P. Moulin (2009). Reverse osmosis desalination: Water sources, technology, and today's challenges. Water Research 43, 2317-2348.

38 S. Zhao, L. Zou, C.Y. Tang and D. Mulcahy (2012). Recent developments in forward osmosis: Opportunities and challenges. Journal of Membrane Science 396, 1-21. 
39 V.G. Gude (2011). Energy consumption and recovery in reverse osmosis, op. cit.; N.C. Wright and A.G.V. Winter (2014). Justification for community-scale photovoltaic-powered electrodialysis desalination systems for inland rural villages in India, op. cit.; H.J. Krishna (2004). Introduction to Desalination Technologies, op. cit.

40 W. Ho and K. Sirkar (eds) (1992). Membrane Handbook. Springer.

41 Y. Oren (2008). Capacitive delonization (CDI) for desalination and water treatment - past, present and future (a review). Desalination 228, 10-29.

42 P.M. Biesheuvel and A. van der Wal (2010). Membrane capacitive deionization. Journal of Membrane Science 346, 256-262.

43 S. Porada, R. Zhao, A. van der Wal, V. Presser and P.M. Biesheuvel (2013). Review on the science and technology of water desalination by capacitive deionization. Progess in Materials Science 58, 1388-1442.

44 LennTech (1998). Desalination Pretreatment.

https://www.lenntech.com/processes/desalination/pretreatment/general/desalination-pretreatment.htm (accessed 1 August 2017)

45 R. Allison (1991). Surface and Wastewater Desalination by Electrodialysis Reversal.

46 H.J. Krishna (2004). Introduction to Desalination Technologies, op. cit.

47 V.G. Gude (2011). Energy consumption and recovery in reverse osmosis, op. cit.; H. Cooley, P. Gleick and G. Wolff (2006). Desalination, With a Grain of Salt: A California Perspective.

48 H. Cooley, P. Gleick and G. Wolff (2006). Desalination, With a Grain of Salt: A California Perspective.

49 H.J. Krishna (2004). Introduction to Desalination Technologies, op. cit.

50 H.T. Nguyen and J.M. Pearce (2010). Renewable Powered Desalination In The Coastal Mekong Delta. American Society of Mechanical Engineers.

51 J.W. Wu, M.J. Biggs and E.J. Hu (2014). Dynamic model for the optimisation of adsorption-based desalination processes, op. cit.

52 K. Walha, R. Ben Amar, L. Firdaous, F. Quemeneur and P. Jaouen (2007). Brackish groundwater treatment by nanofiltration, reverse osmosis and electrodialysis in Tunisia: performance and cost comparison. Desalination 207, 95-106.

53 A.M. Bilton, R. Wiesman, A.F.M. Arif, S.M. Zubair and S. Dubowsky (2011). On the feasibility of community-scale photovoltaic-powered reverse osmosis desalination systems for remote locations. Renewable Energy 36, 3246-3256; T. Abraham and A. Luthra (2011). Socio-economic \& technical assessment of photovoltaic powered membrane desalination processes for India, op. cit..

54 D.D.W. Rufuss, S. Iniyan, L. Suganthi and P.A. Davies (2016). Solar stills: A comprehensive review of designs, performance and material advances. Renewable and Sustainable Energy Reviews 63, 464-496.

55 N.C. Wright and A.G.V. Winter (2014). Justification for community-scale photovoltaic-powered electrodialysis desalination systems for inland rural villages in India, op. cit.

56 H. Cooley, P. Gleick and G. Wolff (2006). Desalination, With a Grain of Salt: A California Perspective.

57 N.C. Wright and A.G.V. Winter (2014). Justification for community-scale photovoltaic-powered electrodialysis desalination systems for inland rural villages in India, op. cit.

58 K. Walha, R. Ben Amar, L. Firdaous, F. Quemeneur and P. Jaouen (2007). Brackish groundwater treatment by nanofiltration, reverse osmosis and electrodialysis in Tunisia, op. cit. 
59 H.T. Nguyen and J.M. Pearce (2010). Renewable Powered Desalination In The Coastal Mekong Delta, op. cit.

60 S.K. Ramasesha and A. Chakraborty (2013). Power generation using wind energy in northwest Karnataka, India. Current Science 104, 757-761.

61 Engineers Australia (2015). World's first wave-powered desalination plant now operational in Perth. https://www.engineersaustralia.org.au/portal/news/worlds-first-wave-powered-desalination-plant-nowoperational-perth (accessed 1 September 2017)

62 K. Thomas (1997). Overview of Village Scale, Renewable Energy Powered Desalination.

63 H.T. Nguyen and J.M. Pearce (2010). Renewable Powered Desalination In The Coastal Mekong Delta, op. cit.

64 P. Sandwell et al. (2016). Off-grid solar photovoltaic systems for rural electrification and emissions mitigation in India. Solar Energy Materials and Solar Cells 156, 147-156

65 J.R. Ziolkowska (2015). Is Desalination Affordable?Regional Cost and Price Analysis. Water Resources Management 29, 1385-1397.

66 There is a surprisingly large price range for solar-powered $\mathrm{RO}$. The values are based on direct quotes obtained from commercial vendors and it is unclear exactly what the reasons are for the large variation in cost.

67 S. Zhao, L. Zou, C.Y. Tang and D. Mulcahy (2012). Recent developments in forward osmosis: Opportunities and challenges. Journal of Membrane Science 396, 1-21.

68 N.C. Wright and A.G.V. Winter (2014). Justification for community-scale photovoltaic-powered electrodialysis desalination systems for inland rural villages in India, op. cit; J.R. Ziolkowska (2015). Is Desalination Affordable?Regional Cost and Price Analysis, op. cit.

69 N.C. Wright and A.G.V. Winter (2014). Justification for community-scale photovoltaic-powered electrodialysis desalination systems for inland rural villages in India, op. cit.

70 SUEZ Water Technologies \& Solutions. Water Pretreatment Chemicals. https://www.suezwatertechnologies.com/products/water-pretreatment-chemicals (accessed 15 September 2017)

71 J.R. Ziolkowska (2015). Is Desalination Affordable? Regional Cost and Price Analysis. Water Resour. Manag. 29, 1385-1397.

72 DOW Factsheet. DOW FILMTEC Membranes - Cleaning Procedures.

http://msdssearch.dow.com/PublishedLiteratureDOWCOM/dh_060a/0901b8038060a66f.pdf?filepath=liquids ..

73 Gov.UK, Department for Environment, Food \& Rural Affairs (2016). Discharges to surface water and groundwater: environmental permits. https://www.gov.uk/guidance/discharges-to-surface-water-andgroundwater-environmental-permits (accessed 1 September 2017)

74 Desalitech (2017). 7 Ways to Dispose of Brine Waste. https://desalitech.com/7-ways-to-dispose-of-brinewaste/ (accessed 1 September 2017)

75 Santa Ana Watershed Project Authority (SAWPA) (2012). Brine Line Administration. http://www.sawpa.org/brineline/ (accessed 1 September 2017)

76 Gov.UK, Department for Environment, Food \& Rural Affairs (2016). Discharges to surface water and groundwater: environmental permits, op. cit. 
78 J.R. Ziolkowska (2015). Is Desalination Affordable? Regional Cost and Price Analysis, op. cit.

79 SAMCO (2017). How Much Will a Zero Liquid Discharge System Cost Your Facility?

https://www.samcotech.com/how-much-will-a-zero-liquid-discharge-system-cost-your-facility/ (accessed 1

September 2017)

80 USAID (2016). Global Waters Radio: Natasha Wright on Solar-Powered Desalination in India. https://medium.com/usaid-global-waters/global-waters-radio-natasha-wright-on-solar-powered-desalinationin-india-1f8bff28a6e4 (accessed 15 September 2017)

81 M.H.I Dore (2005). Forecasting the economic costs of desalination technology. Desalination 172, 207214.

82 J.R. Ziolkowska (2015). Is Desalination Affordable? Regional Cost and Price Analysis, op. cit.

83 T. Abraham and A. Luthra (2011). Socio-economic \& technical assessment of photovoltaic powered membrane desalination processes for India, op. cit.

84 L. Weinstein and R. Dash (2013). Capacitive Deionization: Challenges and Opportunities. Desalination \& Water Reuse 34-37.

85 Ibid.

86 Tata Center (2017). Solar-powered, village-scale electrodialysis water desalination.

https://tatacenter.mit.edu/portfolio/photovoltaic-powered-village-scale-electrodialysis-desalination-systems/;

N.C. Wright and A.G.V. Winter (2014). Justification for community-scale photovoltaic-powered

electrodialysis desalination systems for inland rural villages in India, op. cit.

87 Barefoot College. It starts with the sun. https://www.barefootcollege.org/solution/solar/; Barefoot College. Water: the source of all life. https://www.barefootcollege.org/solution/water/

88 D.C. Hicks (2004). The Delbuoy, a low-cost, low maintenance, wave-powered desalination unit. Horizon International Solutions Site. http://www.solutions-site.org/node/82

89 A WHO report from 2003 found 7.5L/day to be the average minimum water required for an individual for domestic water needs, which includes hydration, food preparation and basic hygiene. G. Howard (2003). Domestic Water Quantity, Service Level and Health.

90 A. Jain (2015). NGO moves Green Tribunal over wastage by RO purifiers. The Hindu. http://www.thehindu.com/news/cities/Delhi/ngo-moves-green-tribunal-over-wastage-by-ropurifiers/article7156320.ece (accessed 1 October 2017); The Hindu BusinessLine (2017). Ban sale of RO filters without ISI certification: NGO tells NGT. http://www.thehindubusinessline.com/news/ban-sale-of-rofilters-without-isi-certification-ngo-tells-ngt/article9606492.ece (accessed 1 October 2017) 



\section{Oxfam Research Reports}

Oxfam Research Reports are written to share research results, to contribute to public debate and to invite feedback on development and humanitarian policy and practice. They do not necessarily reflect Oxfam policy positions. The views expressed are those of the authors and not necessarily those of Oxfam.

For more information, or to comment on this report, email policyandpractice@oxfam.org.uk.

(c) Oxfam International May 2018

This publication is copyright but the text may be used free of charge for the purposes of advocacy, campaigning, education, and research, provided that the source is acknowledged in full. The copyright holder requests that all such use be registered with them for impact assessment purposes. For copying in any other circumstances, or for re-use in other publications, or for translation or adaptation, permission must be secured and a fee may be charged. Email policyandpractice@oxfam.org.uk

The information in this publication is correct at the time of going to press.

Published by Oxfam GB for Oxfam International under ISBN 978-1-78748-245-6 in May 2018.

DOI: $10.21201 / 2018.2456$

Oxfam GB, Oxfam House, John Smith Drive, Cowley, Oxford, OX4 2JY, UK.

\section{OXFAM}

Oxfam is an international confederation of 20 organizations networked together in more than 90 countries, as part of a global movement for change, to build a future free from the injustice of poverty. Please write to any of the agencies for further information, or visit www.oxfam.org

Oxfam America (www.oxfamamerica.org)

Oxfam Australia (www.oxfam.org.au)

Oxfam-in-Belgium (www.oxfamsol.be)

Oxfam Brazil (www.oxfam.org.br)

Oxfam Canada (www.oxfam.ca)

Oxfam France (www.oxfamfrance.org)

Oxfam Germany (www.oxfam.de)

Oxfam GB (www.oxfam.org.uk)

Oxfam Hong Kong (www.oxfam.org.hk)

Oxfam IBIS (Denmark) (http://oxfamibis.dk/)
Oxfam India (www.oxfamindia.org)

Oxfam Intermón (Spain) (www.oxfamintermon.org)

Oxfam Ireland (www.oxfamireland.org)

Oxfam Italy (www.oxfamitalia.org)

Oxfam Japan (www.oxfam.jp)

Oxfam Mexico (www.oxfammexico.org)

Oxfam New Zealand (www.oxfam.org.nz)

Oxfam Novib (Netherlands) (www.oxfamnovib.nl)

Oxfam Québec (www.oxfam.qc.ca)

Oxfam South Africa (www.oxfam.org.za) 